\title{
Prestige or Perish: Publishing Decisions in Academic Archaeology
}

\author{
Jess Beck (i), Erik Gjesfjeld (iD, and Stephen Chrisomalis
}

\begin{abstract}
Success in academic archaeology is strongly influenced by the publication of peer-reviewed articles. Despite the importance of such articles, minimal research has explicitly examined the factors influencing publishing decisions in archaeology. In order to better understand the landscape of archaeological publishing, we distributed a short survey that solicited basic professional and demographic information before asking respondents to (1) identify journals that publish important archaeological research, (2) identify journals that people who read archaeological academic CVs value most highly, and (3) rank the factors that affected their decisions about where to submit an article for publication. Our results from 274 respondents generated a list of 167 individual journal titles. Prestige was viewed as the most important factor that affected publishing decisions, followed by audience and open access considerations. There was no relationship between respondent-generated journal rankings and SCImago Journal Ranks (SJR), but there were significant differences in average SJR by gender and career stage. Responses showed consensus on only a small number of highly ranked archaeology and science-subject journals, with little agreement on the importance of most other journals. We conclude by highlighting the areas of disciplinary consensus and divergence revealed by the survey and by discussing how implicit prestige hierarchies permeate academic archaeology.
\end{abstract}

Keywords: publishing, archaeology, prestige, open access, equity

El éxito en la arqueología académica está fuertemente influenciado por la publicación en revistas revisadas por pares. A pesar de su importancia, muy poca investigación ha examinado explícitamente los factores que influyen en las decisiones que se toman a la hora de seleccionar dónde publicar. Con el objeto de comprender mejor el panorama de las publicaciones arqueológicas distribuimos una breve encuesta solicitando información básica de carácter profesional y demográfica antes de pedir a los encuestados que (1) identificaran las revistas que publican investigación arqueológica importante, (2) nombraran las revistas más valoradas por aquellos que revisan CV académicos, (3) jerarquizaran los factores que influyen en la elección de revistas a la hora de enviar a publicar sus propios manuscritos. Nuestros resultados sobre 274 encuestados generaron una lista de 167 publicaciones periódicas. El prestigio fue destacado como el principal factor en la toma de decisiones, seguido por la audiencia y la publicación en abierto. No se observó relación alguna entre el ranking de revistas generado por los encuestados y los SCImago Journal Ranks (SJR), pero sí diferencias significativas en las medias de SJR por género y etapa en la carrera académica. Las respuestas solo coincidieron en un pequeño número de revistas científicas y de arqueología altamente clasificadas y ofrecieron muy poco consenso en la mayor parte del resto de publicaciones. Concluimos destacando las áreas de consenso y divergencia disciplinar que revelan las encuestas y discutimos cómo las jerarquías de prestigio implícitas impregnan la arqueología académica.

Palabras clave: publicación, arqueología, prestigio, acceso abierto, equidad

Jess Beck (jbeck1@ fas.harvard.edu, corresponding author) — McDonald Institute for Archaeological Research, University of Cambridge, Cambridge, UK; Anthropology Department, Vassar College, Poughkeepsie, New York, USA

Erik Gjesfjeld $\square$ McDonald Institute for Archaeological Research, University of Cambridge, Cambridge, UK

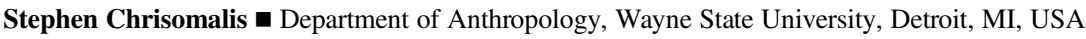

American Antiquity 86(4), 2021, pp. 669-695

Copyright (C) The Author(s), 2021. Published by Cambridge University Press on behalf of the Society for American Archaeology. This is an Open Access article, distributed under the terms of the Creative Commons Attribution-NonCommercialShareAlike licence (http://creativecommons.org/licenses/by-nc-sa/4.0/), which permits non-commercial re-use, distribution, and reproduction in any medium, provided the same Creative Commons licence is included and the original work is properly cited. The written permission of Cambridge University Press must be obtained for commercial re-use.

doi:10.1017/aaq.2021.64 
${ }^{66} \mathrm{P}$ ublish or perish" is the aphorism most frequently used to explain the frenetic productivity that characterizes contemporary academic labor. There are a multitude of forums for the publication of new research, ranging from peer-reviewed journals to conference proceedings, monographs, edited volumes, and books. Within academia, the imperative to publish is so strong that it has led to the emergence of a new breed of "predatory" journals that solicit scholarly work, encouraging recruited authors to pay evaluation or publication fees in exchange for acceptance (Bartholomew 2014; Demir 2018; Xia et al. 2015). These journals have become so prevalent that most scholars who hold an academic e-mail address will be familiar with their spam solicitations. Indeed, a list of potentially predatory journals compiled by librarian Jeffrey Beall ran to 1,099 titles at the end of 2017 (Beall 2020; Demir 2018).

The late twentieth century witnessed a series of notable transformations in both the structure and scale of academic publishing. These changes can be concisely summarized as a trend toward more articles produced by fewer publishers at higher costs to the consumer. There are an increasing number of new journal titles and articles being published annually (Gantz 2013), a phenomenon that has resulted in researchers reading and citing more articles per year, ${ }^{1}$ with concomitant shifts in scholarly reading and information-seeking patterns (Tenopir et al. 2009). The expanding volume of academic publication is partially the result of the growing importance of digital and electronic publishing. The last several decades have seen a decline in personal academic journal subscriptions in tandem with an accelerating institutional shift from print subscriptions to hybrid or electronic-only subscriptions. As journals and academic articles have proliferated, the number of corporations publishing these products has dwindled; smaller academic publishers have increasingly become consolidated into an oligopoly (McGuigan 2004). In 2013, the top five academic publishers ${ }^{2}$ were responsible for distributing more than half of all academic articles published; for the social sciences, this represents more than a $50 \%$ increase in market share in less than two decades (Larivière et al. 2015).
Against the backdrop of the rapidly changing environment of academic publishing, it is important to investigate how and why academics make decisions about where to publish their research, and how academic journals are perceived within disciplines. Research on intradisciplinary perceptions of journal prestige has been conducted in a number of fields ranging from political science to sociology, geography, criminal justice, human development, economics, management, marketing, real estate, business ethics, accounting, social work, and library and information science (Nisonger and Davis 2005:343).

Academic archaeology is a topically diverse field, whose practitioners have variously characterized the discipline as belonging to the humanities or the sciences, ${ }^{3}$ depending on historical moment, subfield, and theoretical inclination (Hawkes 1968; Hodder 2003; Isaac 1971; Martinón-Torres and Killick 2015; Sørensen 2017). The field's small size and epistemological plurality mean that the most widely used forms of bibliometric evaluation are of limited use for assessing the prestige, importance, or influence of peer-reviewed archaeology journals, as we discuss later in this article. ${ }^{4}$ How, then, do archaeologists decide where to publish their research?

In this article, we investigate publishing decisions within the field of academic archaeology. In April 2019, we distributed an online survey that asked participants a series of questions about academic journals and the factors that affected their publishing decisions, along with nonidentifying demographic and professional data. There were 274 archaeologists who responded. Our survey was designed to collect data that would allow us to answer the following questions:

(1) How diverse is the landscape of archaeological publishing?

(2) To what degree do archaeologists' perceptions of journal prestige match bibliometric journal rankings?

(3) How do respondents' gender and career stage relate to the perceived prestige of journals?

(4) What factors do archaeologists say they are considering when they decide where to publish an academic article? 


\section{Prestige and the Sociopolitics of Academic Archaeology}

Archaeology has grown increasingly selfreflexive over the past 40 years, a turn evidenced by the slew of recent publications on the dynamics of archaeological knowledge production. Such work has investigated citational practices (Bardolph 2014; Hutson 2002), authorship (Bardolph 2018; Bardolph and Vanderwarker 2016; Fulkerson and Tushingham 2019; Heath-Stout 2020a, 2020b; Tushingham et al. 2017), grant funding (Goldstein et al. 2018; Yellen 1994), the demographic composition of the field (Jalbert 2019), open archaeology and data availability (Huggett 2015; Lake 2012; Marwick and Birch 2018; Marwick et al. 2017; Wilson and Edwards 2015), and scholarly publishing (Costopoulos 2017a, 2018; Fogelin 2019, 2020). This new research is rooted in earlier work on identity and ideology that sought to explicitly examine the sociopolitics of archaeology as a field (Gero 1985; Gero et al. 1983; Meskell 2002). These disciplinary meta-analyses move beyond investigating patterns in funding and scholarship to questioning the social and logistical frameworks that undergird the operation of the profession. Such studies include investigations of the safety and accessibility of archaeological fieldwork (Colaninno et al. 2020; Heath-Stout and Hannigan 2020; Meyers et al. 2018; Radde 2018; Voss 2021a, 2021b), the "chilly climate," gendered disciplinary culture, and "performative informality" that structure professional social networks (Baxter 2005; Leighton 2020; Moser 2007; Overholtzer and Jalbert 2021; Wylie 1993), and the difficulties in achieving work-life balance within the field (Barber 2012; Nelson and Crooks 1994). This work has largely focused on evaluating obstacles to equity and accessibility within archaeology, investigating how the identities of archaeologists intersect with their experiences of and participation in the discipline. These inquiries are not unique to archaeology but reflect larger concerns about accessibility, impact, and inequality within the broader discipline of anthropology (see Clancy et al. 2014; Jobson 2020; Kawa et al. 2019; Nelson et al. 2017).

This growing body of research on the "sociopolitics" (sensu Gero et al. 1983) of archaeology and anthropology has consistently demonstrated the importance of institutional prestige in academic hiring networks (Kawa et al. 2019). Within anthropology, recent studies have shown that the shrinking number of tenure-track jobs available are disproportionately awarded to graduates of particular departments (Kawa et al. 2019). The same pattern, whereby a minority of departments dominate the academic market, has been observed within the subfield of archaeology, where the percentage of archaeology $\mathrm{PhDs}$ hired into tenure-track positions in anthropology departments has declined precipitously since the "Great Recession" of 2007-2008 (Speakman, Hadden, Colvin, Cramb, Jones, Jones, Kling, et al. 2018). Prestige is unarguably also an important factor in academic publishing. As Larivière and colleagues (2015) argue, although academic publishers no longer fulfill their original logistical roles of printing and distribution,

Unfortunately, researchers are still dependent on one essentially symbolic function of publishers, which is to allocate academic capital, thereby explaining why the scientific community is so dependent on "The Most Profitable Obsolete Technology in History." Young researchers need to publish in prestigious journals to gain tenure, while older researchers need to do the same in order to keep their grants, and, in this environment, publishing in a high impact Elsevier or Springer journal is what "counts" [13].

The decreasing demand for print subscriptions means that publishers are no longer paying the costs associated with printing and distributing their products, and electronic publishing is buttressed by considerable economies of scale (Larivière et al. 2015). In the absence of regulation, the decoupling of production costs from subscription fees has led to marked increases in the prices of journal subscriptions, which continue to rise faster than the rate of inflation (Van Noorden 2013). Commercial academic publishers have leveraged this new publishing landscape to their benefit, with estimated profit margins that range from $20 \%$ to $50 \%$ (Larivière et al. 2015; Van Noorden 2013; Wenzler 2017). The skyrocketing costs of journal 
subscriptions have generated a growing interest in the open access (OA) movement among academics, researchers, and librarians, although this proposed alternative system also comes with its own costs, in the form of open access fees and article processing charges (APCs; Antell et al. 2016). The emergence of novel OA expenses leads to the pertinent question of who will pay these costs, especially as APCs are also rising faster than the rate of inflation (Khoo 2019) — a trend that has reached its apotheosis with Nature's recent decision to offer authors an open access option for a paltry US\$11,390 per article (Else 2020).

Another professional concern is how publishing on open access platforms will affect academic careers given the increasing weight accorded to impact factors and citation counts in professional academic assessments (Antell et al. 2016:325), ${ }^{5}$ one of the many forms of "coercive accountability" (Shore and Wright 2000) that characterizes the "audit cultures" of the contemporary academy (Strathern 2000). Despite their recurring use in various forms of academic evaluation, there are serious limitations to using bibliometric indicators to assess journal impact or quality. As we outline in the next section, this is especially true for interdisciplinary Social Sciences and Humanities (SSH) fields such as archaeology, so it is unclear how, precisely, archaeologists make commensurable decisions about the journals best suited to accrue academic capital. Indeed, archaeologists focused on examining the structure and practices of the discipline often underscore the importance of prestige without explicitly outlining how it is acquired. For example, Bardolph admits that "there are a number of ways to measure prestige, and, in many cases ... contributions to a particular field may be substantial but have low visibility, or be difficult to measure or quantify (e.g., research disseminated in gray literature, which is often cited frequently in peer-reviewed literature)" (Bardolph 2014:523). Her examination of publishing trends, however, employs a category encompassing "five major research journals with high visibility and prestige" (Bardolph 2014:526) ${ }^{6}$ without indicating how these indicators were assessed. Her framing provides an apt demonstration of the disciplinary assumption that the level of prestige attributed to particular archaeological journals is both obvious and uncontroversial.

Even research that explicitly defines prestige using some form of quantifiable proxy foregrounds the limitations of such framings. In her examination of the relationship between author demographics and journal prestige, Heath-Stout (2020a) used three bibliometric indicators (IF, $\mathrm{SJR}$, and $h$-index) as measures of journal prestige, with the explicit caveat that all three metrics are grounded in evaluating citations and therefore are not necessarily correlated with the number of people reading a publication or with its disciplinary importance.

In their study of social networks in academic anthropology, Kawa and colleagues (2019) used the variables of average citations per faculty member, awards per faculty member, and average GRE score of admitted graduate students as proxies for departmental prestige. The authors were, however, quick to underscore that academic prestige is not necessarily linked to either merit or productivity, emphasizing that departmental prestige is instead tied to the financial and social capital of the parent institution, which furnishes resources and benefits that can lead to career achievements for faculty (Kawa et al. 2019:16). The results of their network analysis demonstrated that the prestige of the PhD-granting departments had significant impacts on faculty placement for program graduates. Importantly, they hypothesize that average number of citations per faculty may be itself inextricably linked to departmental prestige:

The very condition of being a faculty member at an elite program like Chicago is likely to have influence on this variable. Not only is an article published by a Chicago professor more likely to garner attention than one published by a professor at a less prestigious program, but it is also likely that the Chicago professor is going to have graduate students that will cite and assign that article when they become professors. Not to mention this Chicago professor's colleagues can recommend the work to their influential friends. These cascading effects are important for considering the perpetuation of the 
"academic caste system," as Burris (2004)

describes it [Kawa et al. 2019:24].

The implication that the prestige and renown of an author's department may in and of itself affect citations has additional implications as source of bias in the bibliometric indicators most commonly used to measure impact.

Academic career achievements are not only linked to departmental reputation; prestige in other professional domains also matters. Despite acknowledging the limitations of peer-reviewed publications for measuring disciplinary contributions, Bardolph (2014) emphasizes that the prestige associated with peer-reviewed publications is a key factor in the acceptance and perpetuation of particular archaeological narratives, as well as the constitution of academic capital. Fulkerson and Tushingham (2019:392) likewise draw links between prestige, publishing, and career success to highlight "the professional and social capital that comes with publication and positions of power and prestige" in archaeology. These understandings are echoed by Heath-Stout, who notes that publications-"especially those in the most prestigious and oft-cited journals-are essential for hiring, tenure, and promotion decisions in academia, as well as funding decisions at many granting agencies" (Heath-Stout 2020a:16).

Such studies demonstrate that although attempts to measure prestige directly are imperfect, understandings of academic prestige still have a disproportionate impact on professional trajectories. Given the links between peerreviewed publications, academic capital, and career prospects, deciding where to publish scholarly research is an important consideration. Within academic archaeology, however, prestige is an amorphous and underexamined concept that incorporates two key assumptions. The first is that disciplinary understandings of prestige correlate with some form of academic value (intellectual merit, popularity, productivity, contributions to career advancement, etc.). Important steps toward testing the validity of the first assumption have already been made for both archaeology and anthropology (Kawa et al. 2019; Speakman, Hadden, Colvin, Cramb, Jones, Jones, Kling et al. 2018; Speakman,
Hadden, Colvin, Cramb, Jones, Jones, Lulewicz, et al. 2018). The second assumption is that our systems for evaluating prestige are in some way commensurate - in other words, that there is strong intradisciplinary agreement as to which venues are the most prestigious. Our work contributes to this growing body of research by examining whether individuals' rankings of journal importance correspond to bibliometric indicators of impact, or whether disciplinary prestige hierarchies are rooted in other systems of value. Our survey also evaluates the degree of disciplinary consensus regarding the journals considered important for publishing research and enhancing CVs, examining the extent to which these prestige hierarchies are held in common. Finally, we evaluate the factors that shape publishing decisions in academic archaeology by asking respondents to rank an existing list of influences and also detailing any additional considerations. In so doing, our work provides a valuable contribution to studies of academic prestige by explicitly interrogating how archaeologists rank journals relative to one another and make decisions about where to publish their research.

\section{Materials and Methods}

\section{Survey Methods}

During the first phase of our Publishing Decisions in Archaeology (PDIA) project, a small-scale pilot survey was circulated internally to members of the McDonald Institute for $\mathrm{Ar}$ chaeological Research at the University of Cambridge in November and December 2018, targeting archaeologists at the level of $\mathrm{PhD}$ student or higher. The pilot survey was designed to evaluate whether our question structure produced data sufficient for answering our research questions. After evaluating the data collected during the pilot phase of the project, the survey structure was slightly modified in order to increase our response rate and refine our data collection methods. ${ }^{7}$

The second phase of the survey used a structure similar to the pilot phase, with an initial section that solicited demographic and professional information. This included gender, age, nationality, native language, primary publishing 
language, career stage, country in which highest degree was received, and country/countries in which currently employed (Table 1). Recent professional surveys in the United States and the United Kingdom have shown that archaeology is a field striking in its racial homogeneity, with an overwhelming majority of practitioners identifying as white (see White and Draycott [2020] for a concise summary). As a result, we did not ask respondents for information about race/ethnicity because sample sizes were all but guaranteed to be insufficient. Research on the sociopolitics of archaeology has also begun to emphasize the utility of intersectional approaches that address multiple aspects of identity, including sexual orientation, disability, and class background (Heath-Stout 2019). The relationship between these aspects of identity and publishing decisions is an important question. However, a rigorous analysis would require soliciting a more targeted sample than the survey circulated here. Although the aspects of identity targeted by our survey were therefore not exhaustive, they reflect what we would be best positioned to capture in a general sample of several hundred archaeologists.

The second section of the survey asked respondents to (1) identify journals that publish important archaeological research, (2) identify journals that people who read archaeological academic CVs value most highly, (3) rank the factors that affected their decisions about where to submit an article for publication, and (4) list any other factors not included in Question 3 that affected their decisions about where to submit an archaeological article for publication.

The survey was publicized on social media, such as on archaeologically themed Facebook pages and on Twitter. We also publicized the survey through e-mailing colleagues and asking them to circulate the survey in their home departments via e-mail. The second survey was available from April 8, 2019, to July 8, 2019 (92 days).

Ethical approval for both phases of the survey was granted through application to the Departmental Ethics Committee of the Department of Archaeology and Biological Anthropology in the School of the Humanities and Social Sciences at the University of Cambridge.
Participants were not financially compensated during either phase of the survey. The combined demographic and professional information collected does not constitute personal data because the international scale of the survey effectively anonymized participants. When not undergoing analysis, data were stored in Qualtrics, a platform that is General Data Protection Regulation (GDPR) compliant. ${ }^{8}$

\section{Statistical Methods}

Data generated from our survey can be broadly divided into four categories: (1) the demographic information of each respondent, (2) a ranked listing of journal names from Questions 1 and 2, (3) a ranked list of the factors that influence where to publish from Question 3, and (4) comments provided by respondents. The first steps of our data analysis involved the cleaning of data downloaded from Qualtrics. This included the removal of responses that did not answer at least one question, the standardization of journal names provided by respondents, and the classification of demographic information into broader categories. In addition to the data generated from the survey, we also gathered SCImago Journal Rankings (SJRs) for the journals listed by respondents. The SJR scores were obtained from the SCImago website (www.scimagojr.com) for the year 2018, which is the last complete year prior to the survey. In total, 167 unique journal titles were listed by respondents, with SJR scores available for 122 (73\%) of the journal titles.

Using the cleaned data, we tabulated the demographic information of respondents as well as the journal names that were provided for Questions 1 and 2. We also calculated the mean SJR score for each respondent based on the individual's listed journals. This value was determined by averaging the SJR scores for the six journals listed by each respondent for Question 1 and the three journals listed by each respondent for Question 2, although some respondents provided fewer than the requested number of journals. For Question 3, we used the raw rankings (1-8) provided by respondents for the factors that influence their publishing decisions.

All data transformations and visualizations were performed in the $\mathrm{R}$ statistical environment 
Table 1. Phase II PDIA Survey Introductory Text and Questionnaire.

This survey is being conducted by scholars at the McDonald Institute for Archaeological Research and Wayne State University. This project is focused on collecting data that will help us to better understand publishing decisions in archaeology.

The survey should take between 5 and 10 minutes to complete. In completing this survey, you will be asked for demographic and professional information, as well as questions about journals that publish archaeological research, and how you, and others, make decisions about which journals to publish in.

Your participation is entirely voluntary, and you can withdraw from the survey at any time.

The data we are collecting are nonidentifiable. These data will be stored in Qualtrics and on laptops with updated operating systems and antimalware software. We plan to disseminate the results of this research in academic publications that will be made publicly available on our academic websites and the University of Cambridge Apollo repository.

If you have any questions about the survey or require any further information, please contact Dr. Jess Beck.

\section{DEMOGRAPHIC INFORMATION}

Gender (text box to be filled in)

Age (check box with 10-year age ranges)

- $18-29$

- 30-39

- 40-49

- 50-59

- $60-69$

- 70-79

- 80-89

- $90+$

Nationality (text box to be filled in)

Native language(s) (text box to be filled in)

Primary language in which you publish (text box to be filled in)

Career stage (e.g., PhD student, post-doctoral researcher, lecturer) (check box)

- Master's student

- PhD student

- Post-Doc

- Visiting Professor

- Assistant Professor

- Associate Professor

- Full Professor

- Emeritus Professor

- CRM / Contract Archaeologist

- Other

Country in which highest degree was received (text box to be filled in)

Country/countries in which currently employed (text box to be filled in)

\section{SURVEY QUESTIONS}

1. List six journals that publish important archaeological research based on your opinion of their relative importance. (text boxes to be filled in and ranked from 1 [Highest] to 6 [Lowest])

2. List the three journals that, in your opinion, people who read archaeological academic CVs value the most. These do not need to be drawn from the journals listed in the previous question. Rank these journals from highest (1) to lowest (3) in terms of their importance relative to one another, in your opinion. (text boxes to be filled in and ranked from 1 [Highest] to 3 [Lowest]) 3. Rank the following factors in deciding where to submit an archaeological article, with the most important factor listed highest/first: (factors were randomized in Qualtrics; participants dragged boxes into their preferred rank order)

Perceived prestige of journal

Pertinent audience

Open Access

Journal impact factor

Duration of review process

Acceptance rate

Personal relationships

Professional obligation

4. Are there any other factors that you were not able to list in Question 3 that affect your decision as to where to submit an archaeological article? If so, please explain why. (text box to be filled in)

Note: Question form is indicated in italics. 
(R Core Team 2020) using a combination of base functions as well as functions associated with the "tidyverse" (Wickham et al. 2019). The workflow and code for the data transformation and analysis can be found in the online repository for this project at https://doi.org/10.6084/m9.fig share.c.5256425 or at https://github.com/erik gjes/Prestige-or-Perish-Publishing-Decisions-inAcademic-Archaeology.

\section{Periodical Metadata and Journal Metrics}

A central aim of our research is to explore how journal reputations influence decisions about where archaeologists decide to publish. Using Ulrich's Global Serials Directory (2020), we gathered journal metadata for the 167 journals named by survey respondents. These metadata include publication formats, publisher, country, start year, frequency, text language, serial type, description, and subject categories for each periodical, and they are available in Supplemental Data 1. Although our survey questions asked respondents to list "journals," $8 \%$ of the titles generated came from alternate serials types, including directories, magazines, monographic series, proceedings, and yearbooks. In subsequent text, however, we use the term "journals" to refer to all of the titles generated by our survey, because the majority of our sample (92\%) consisted of this type of serial.

In addition to journal metadata, we collected quantitative journal metrics. It is important to note that significant challenges exist in selecting a rigorous bibliometric indicator appropriate to the social sciences and humanities. In SSH fields, local or regional research orientations are more common, more work is published in books, the pace of theoretical development is often slower, single-scholar publications are more common, and a higher proportion of publications are produced for the general public rather than specialists (Nederhof 2006). As a result of these differences, the unreflective use of bibliometric indicators to measure impact can be limiting for disciplines outside of the natural sciences. For example, a greater proportion of journals from SSH disciplines are not included in the popular parent databases, such as Web of Science and Scopus, which are used to calculate the most widely employed bibliometric indexes. In addition, publication formats popular in SSH fields-including conference presentations, reports, gray literature, chapters in edited volumes, books, and monographs-are "essentially excluded" from such databases (Bornmann et al. 2016:2779; Kosmopoulos and Pumain 2007).

Here, we considered three bibliometric indicators: journal impact factor (JIF), SCImago Journal Rankings (SJR), and the $h$-index. In general, most journal metrics count the number of times an article in a journal has been cited in other works, although differing algorithms and methods will cause metrics to differ from each other. One of the first and most common metrics is the JIF, which measures the frequency with which the "average" article in a particular journal is cited during a two-year period. ${ }^{9}$ Although the JIF provides a means of quantifying differences in citation frequencies between journals, researchers have long cautioned that the equation of JIFs with the importance or quality of the published research is overly simplistic. Over 20 years ago, Seglen (1997:Table 6) identified a series of problems linked to using JIFs as proxies for prestige, including his observation that overall citation counts correlate with both research field and language of publication, with journals from smaller fields or journals published in languages other than English receiving lower numbers of citations.

As a result of these limitations, alternatives such as the SCImago Journal Rank (SJR) and the $h$-index have been proposed as bibliometric substitutes. SJR indicators express "the average number of weighted citations received in the selected year by the documents published in the selected journal in the three previous years" (https://www.scimagojr.com/help.php). SJR indicators are specifically designed to be a measure of journal prestige, with the current prestige of a journal being based on the prestige of the set of journals that previously cited the journal. Here, we rely on SJR as a measure of journal prestige because it provides a number of advantages for our study, including its open access nature, its use of a broader parent database that incorporates journals of a greater variety of languages and nationalities, and its ability to weight citations by journal influence (Falagas et al. 2008). However, SJR rankings are still beset by some of the same limitations as the JIF-namely, 
that field-specific journals from smaller disciplines will produce a much narrower range of scores. In addition to JIF and SJR, we also considered the $h$-index, which has been predominantly used as a measurement of the "impact and relevance of an individual's scientific research output" (Hirsch 2005:16569; italics ours). For example, an $h$-index of 10 indicates that a scholar has published at least 10 articles that have at least 10 citations each. The $h$-index is therefore distinct from the JIF or the SJR in that it quantifies the impact of a scholar's entire body of published articles rather than the impact of the journals in which their work has been accepted. Similar to other metrics, the $h$-index comes with its own set of limitations, including difficulty comparing across disciplines and dependency on the coverage and accuracy of citation databases (Norris and Oppenheim 2010).

\section{Results}

The second and larger version of our survey received 279 responses, 274 of which could be used in our analysis after data cleaning. The composition of our sample by gender, age, and career stage is outlined in Figure 1. The demographic and professional characteristics of the respondents can be found in Supplemental Data 2. Respondents were divided approximately evenly by gender, with the majority of our sample composed of mid-career academic archaeologists educated and employed in the United States or the United Kingdom, publishing predominantly in English.

\section{How Diverse Is the Landscape of Archaeological Publishing?}

In response to Questions 1 and 2, respondents provided a total of 167 unique journal titles. To assess the composition of these journals, we cross-referenced the survey data with metadata provided by Ulrich's database (Ulrich's Global Serials Directory 2020), which revealed a number of noteworthy sample characteristics. First, although most of our respondents came from North America, the majority of the journals they cited were based in Europe (62\%). When journal origins are broken down by country, however, the majority of titles were published in the UK $(62 / 167,37 \%)$, followed closely by the United States $(57 / 167,34 \%)$. Unsurprisingly, given their countries of origin, $78 \%$ of the titles in our sample were published in English, 14\% were published in multiple languages, and $8 \%$ were published in a single language other than English. Although the oldest title in our sample had been in operation for 188 years, most of the journal titles generated by our survey were relatively recent: $63 \%$ were started after 1960 , and $30 \%$ started publication in the last 30 years.

The data from Ulrich's also provide a means of examining the diversity of subjects in the current publishing landscape of archaeology (Figure 2). Here, we cross-referenced the journals listed by respondents with the subject area as assigned by Ulrich's. In total, two-thirds of the titles generated by our respondents were categorized as pertaining to archaeology, whereas the remaining third did not have archaeology as one of their subject classifications. Within these journals, the most common subject categories after archaeology were anthropology (15\%), sciences-comprehensive works $(6 \%)$, classical studies (5\%), European history $(5 \%)$, geology (3\%), and paleontology (3\%). All other subject categories represented $\leq 3 \%$ of our survey titles. Summaries of the composition of the respondent-generated sample of journal titles relative to different categories of Ulrich's metadata can be found in Supplemental Data 3.

\section{To What Degree Do Archaeologists' Perceptions of Journal Rankings Match Independent and} Quantitative Journal Rankings (e.g., Journal Impact Factors or SCImago Journal Rankings)?

Results from our survey indicate that quantitative journal rankings, as measured by SJR, do not match the journals that are most commonly listed by respondents. The three highest SJR scores for the journals listed by respondents are from Cell (25.98), Nature (16.35), and Science (13.25), although Cell was listed by only one respondent. The three journals that were most commonly listed in the survey are the Journal of Archaeological Science, Antiquity, and American Antiquity, all of which have much lower and relatively similar SJR scores (J. Archaeol. Sci.: 1.25; Antiquity: 0.82; Am. Antiq.: 1.24). The vast majority of journals listed by respondents (93\%) have an SJR below 2, or they are not 


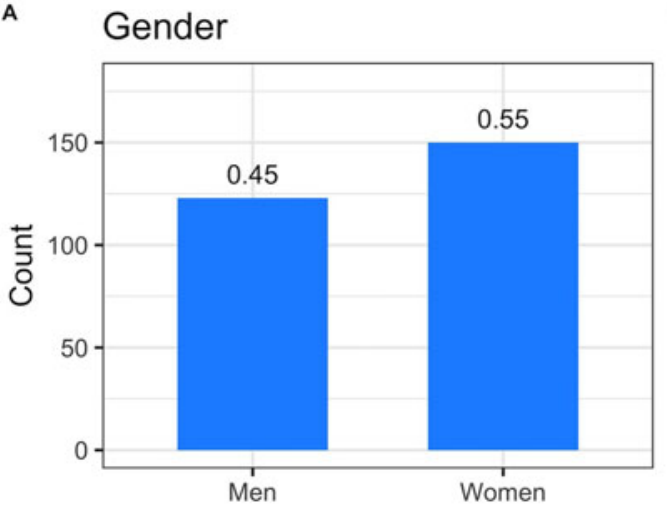

B $\quad$ Age

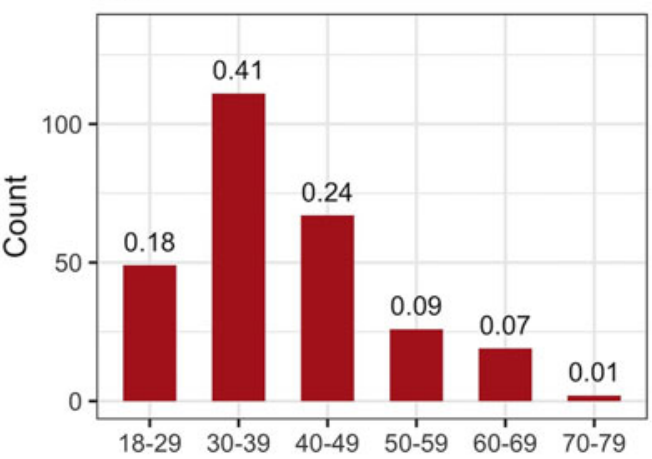

C

\section{Career Stage}

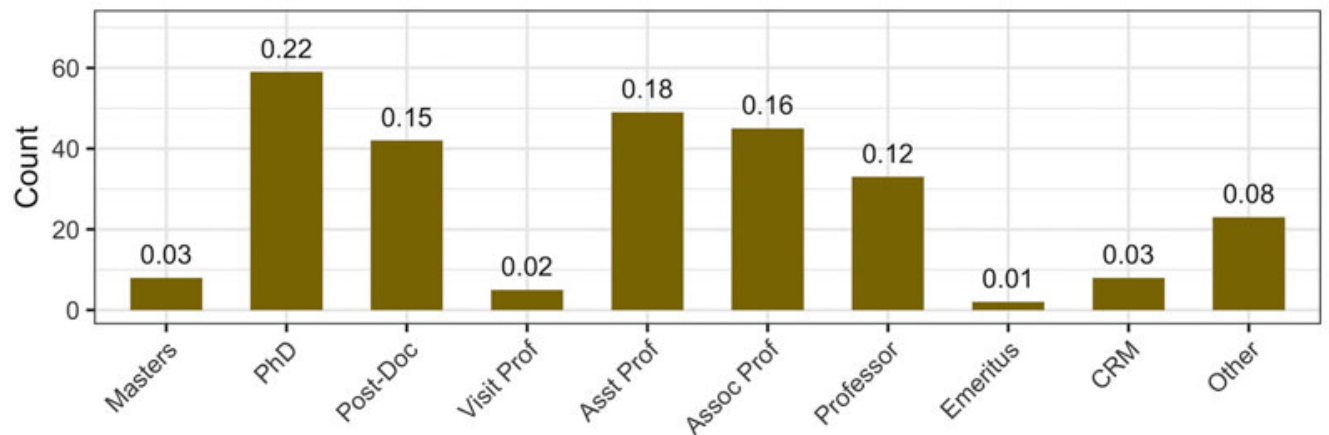

Figure 1. Summary of the gender, age, and career stage of survey respondents. Values represent the proportion of each response within each demographic category.

prominent enough to be given a SCImago rank. This suggests that journals with high SJR scores have little influence on the journals that archaeologists think publish important archaeological information or are important for academic CVs. The exceptions to this trend are the journals $\mathrm{Sci}$ ence and Nature, because the relative ranking of these journals increased from eighth and ninth in Question 1 (Figure 3a) to second and third in Question 2 (Figure 3b).

How Do Respondents' Gender and Career Stage Relate to the Perceived Prestige of Journals?

In light of previous research in academic archaeology demonstrating that personal identity and professional considerations affect authorial behavior (Bardolph 2014; Heath-Stout 2020b), we examined how the gender and career stage of respondents related to the prestige of journals listed in our survey. For Questions 1 and 2, we calculated the average SJR score for each individual based on the SJR scores of journals that were provided by each respondent. These measures were then divided by gender (men/ women) and career stage. In order to simplify our analysis, we classified each career stage provided by respondents as either a tenure-track or a non-tenure-track position. Tenure-track positions include Assistant Professor, Associate Professor, Full Professor, and Emeritus Professor. Nontenure-track (Non-TT) positions include Master's students, PhD Students, Post-Docs, Visiting Professors, CRM / contract archaeologist, and all other categories. Our primary goal in this survey was to examine the publishing dynamics of academic archaeology, and we acknowledge that the professional landscape of CRM archaeology is distinct enough that 


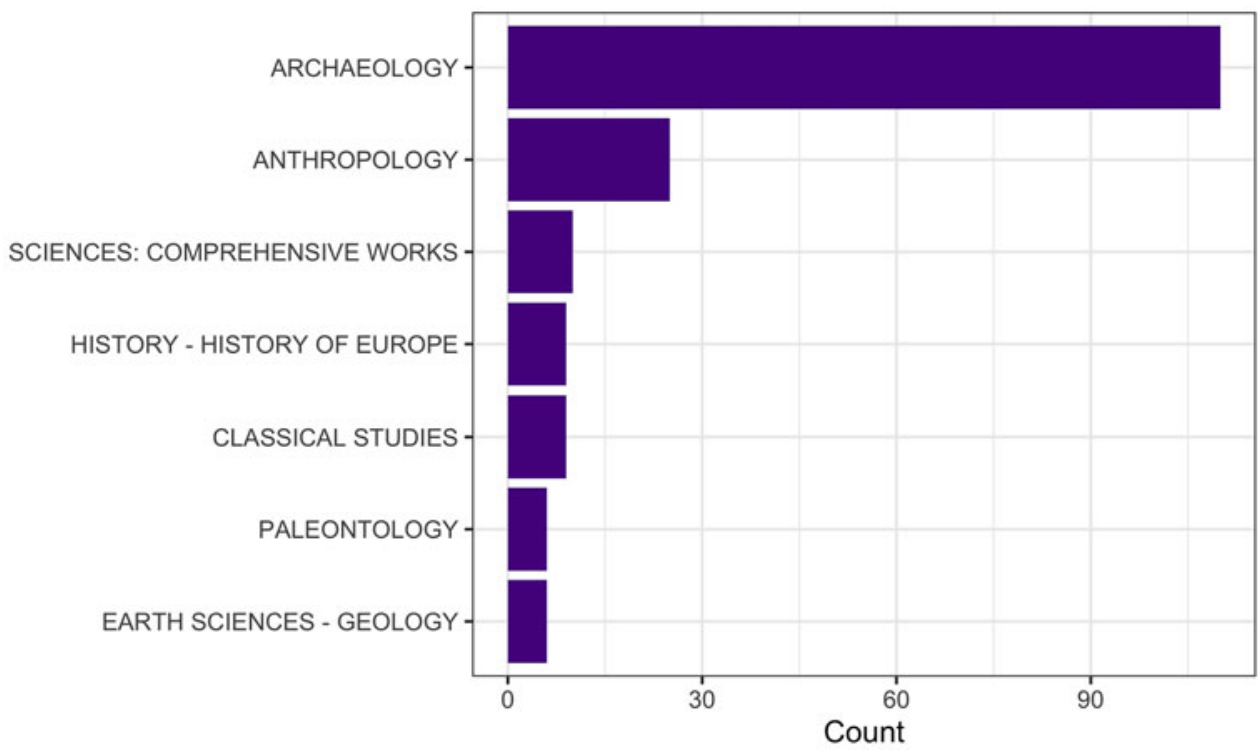

Figure 2. Distribution of journal subject areas (as classified by Ulrich's) for the journals listed by respondents in our survey. Note that journals can have multiple subject classifications.

our conclusions here cannot be projected onto that field. ${ }^{10}$ The number of CRM archaeologists who responded to the survey $(n=8,3 \%)$, however, was too small to create a separate analytical category. Rather than omit these data, we added these individuals into the Non-TT group.

When comparing these categories, we do not see any significant difference between genders (Figure 4a) when evaluating journals that publish important archaeological research (Question 1), based on the results of nonparametric MannWhitney-Wilcoxon test $(W=9951, p$-value $=$ $0.2147)$. However, significant differences $(W=$ $10,448, p$-value $=0.0032$ ) between SJR means are found between men and women when listing journals valuable to academic CVs (Figure 4c), with men tending to list journals with higher SJR scores. When examining career stage, significant differences are found between tenuretrack and non-tenure-track survey participants (Q1: $W=7,691, \quad p$-value $=0.0142 ; \quad \mathrm{Q} 2: \quad W=$ $7,036.5, p$-value $=0.0059)$. For both Questions 1 and 2 (Figures $4 \mathrm{~b}$ and $4 \mathrm{~d}$ ), journals listed by non-tenure-track respondents tend to have a higher SJR score than journals listed by tenuretrack respondents.
What Factors Do Archaeologists Say They Are Considering When They Decide Where to

Publish an Academic Article?

This issue was directly addressed by the third question in our survey, in which we asked respondents to rank eight factors they consider when deciding to publish an academic article. "Perceived prestige of journal" and "Pertinent audience" were the factors that were most highly ranked by respondents (Figure 5). "Prestige" was ranked first by $27 \%$ of respondents, and second by $43 \%$ of respondents, with a median rank of 2. Similarly, "Audience" was ranked first by $32 \%$ of respondents, and second by $20 \%$ of respondents, and also had a median rank of 2. The third most important factor for respondents was "Open Access"- $37 \%$ of respondents ranked this factor either first or second. The remaining factors in order of their median ranks were "Impact factor," "Duration of review process," "Acceptance rate," "Personal relationships," and "Professional obligations." In addition to having respondents rank predetermined factors, we included an open-ended question (Question 4) asking respondents to describe any additional factors that affected their decisions about where to submit archaeological articles. In total, 85 

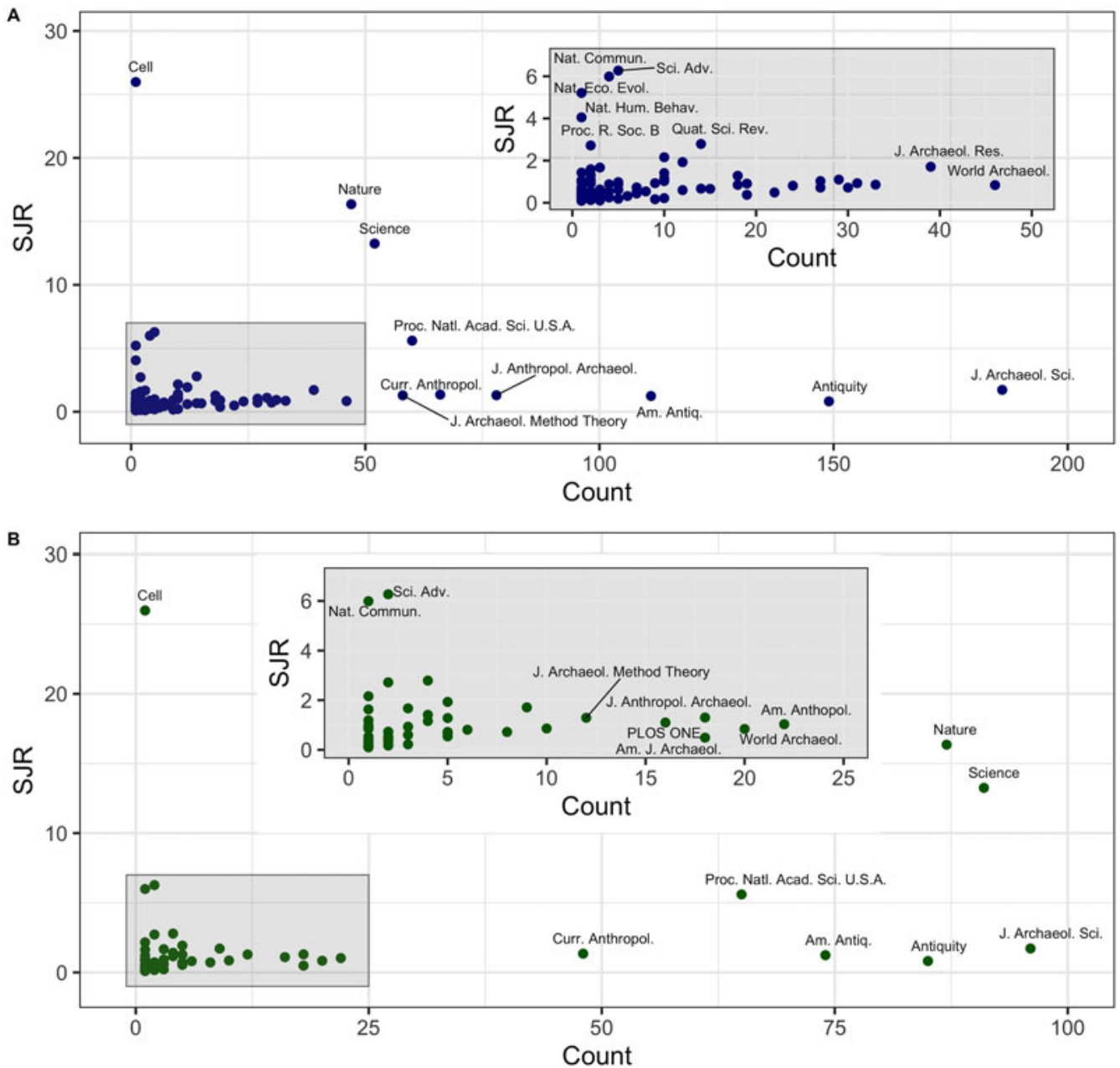

Figure 3. Scatterplot of the relationship between SCImago Journal Ranking (SJR) and the number of times each journal was listed in our survey (Count) for (a) Question 1 and for (b) Question 2. The shaded insets magnify the cluster of journals that have lower SJR scores and were not often mentioned in our survey results. Journal titles have been abbreviated using ISO 4 standards.

out of 274 participants $(31 \%)$ responded to this question, with comments listed individually in Supplemental Data 4. These comments can be divided into four major categories: issues of fit and relevance, consideration of ethics and diversity, career implications, and logistical considerations.

Fit and Relevance. Questions of fit and relevance were raised by 19 out of 85 respondents $(22 \%)$, suggesting that there is some distinction being made by participants beyond our factor "Pertinent audience." Respondents underscored the need to select an appropriate journal for submission based on its topical orientation and publication history. In addition to the ultimate audience (readership) for an article, fit encompasses the question of the scope and nature of articles likely to be well received by journal editors themselves:

Whether or not a paper is technical, methodological, or theoretical, as opposed to presenting new results will also have a big impact on where I decide to submit, since different journals value these considerations differently. (19) ${ }^{11}$

Another framing of the issue of fit reflects attention not to audience but to the similarity of one's work to previous articles in a journal, whether 
A Gender

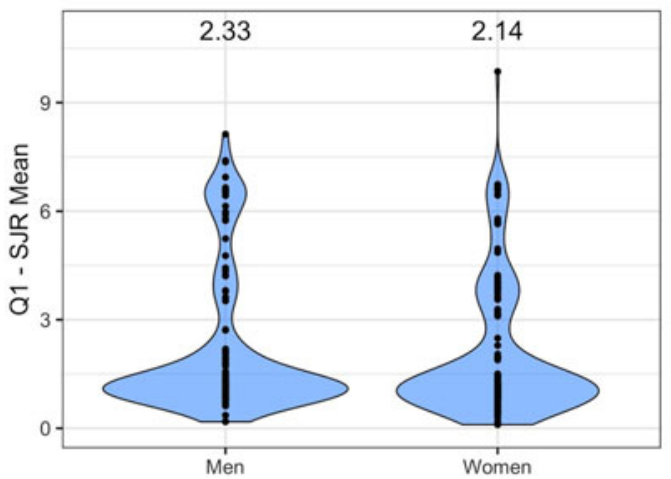

$c^{* *}$

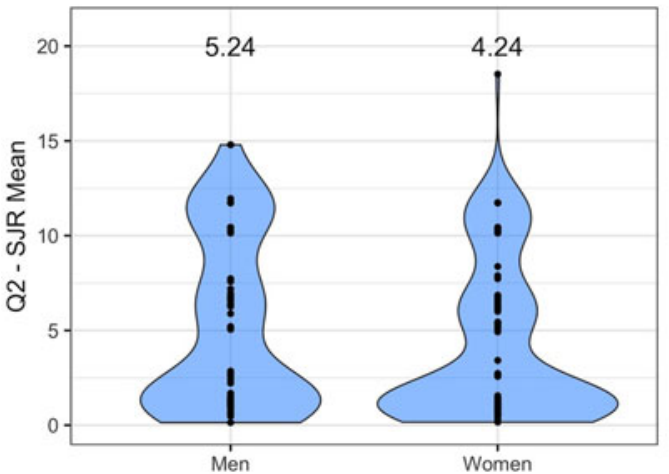

$B^{*}$ Career Stage

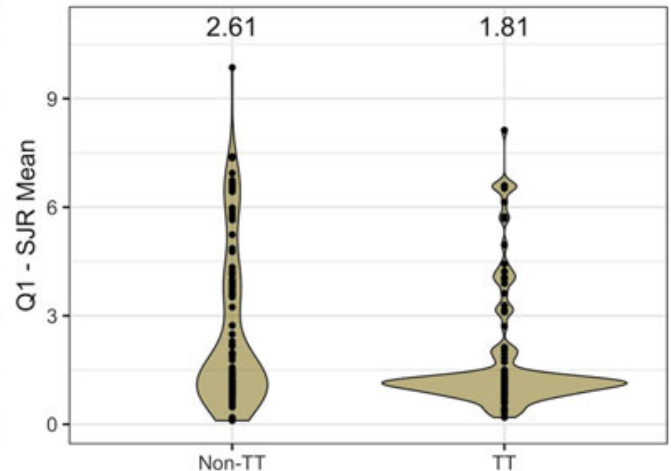

D**

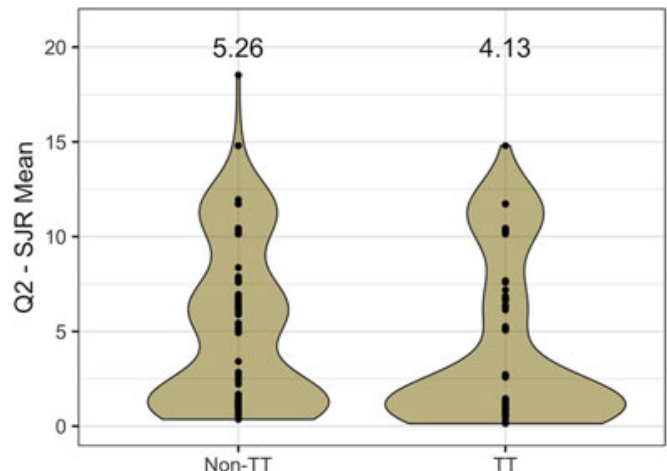

Figure 4. Violin plots indicating the mean SJR scores per respondent for survey Questions 1 and 2. Data is divided by gender (Men/Women) and career stages, which are grouped as Tenure-Track (TT) positions (Assistant Professor, Associate Professor, Full Professor, Emeritus Professor) and Non-Tenure-Track (Non-TT) positions (Master's, PhD, PostDoc, Visiting Professor, CRM / Contract Archaeologist, Other). Significant differences between grouping, based on a two-sample t-test, are indicated by the number of stars $\left(p<0.001 * * * ; p<0.01 * * ; p<0.05^{*}\right)$.

based on regional focus, methodology, or theoretical bent. The signal influencing decisionmaking, for such respondents, is not the intended audience per se but rather previous published work in that journal:

I put a lot of value in trying to publish in journals where I see articles that inspire me and invoke the kinds of research questions, designs, and interpretations that I conduct. So instead of an emphasis on pertinent audience, I'm talking here about an emphasis on pertinent scholarship. (192)

Only three respondents used the word "fit" in their responses, and we had intentionally chosen not to use that word in any of our named factors. Unpacking the culturally complex concept of "fit" among academic writers (in archaeology and elsewhere) is beyond the scope of this article, but it is a highly pertinent topic for future research. Briefly, it might be suggested that fit is a schema or cultural model (d'Andrade and Strauss 1992), parts of which may be shared widely across disciplines, and parts of which may have disciplinespecific meanings. For instance, we anticipate that "fit" in hiring has a different meaning than "fit" in the context of journal selection (Gaspar and Brown 2015). In coming together under a coherent term, "fit" forms a significant part of discussions around publishing decisions in different disciplines and different contexts.

Ethics and Diversity. Although we did not explicitly include a response option relating to ethical commitments in our survey, our 

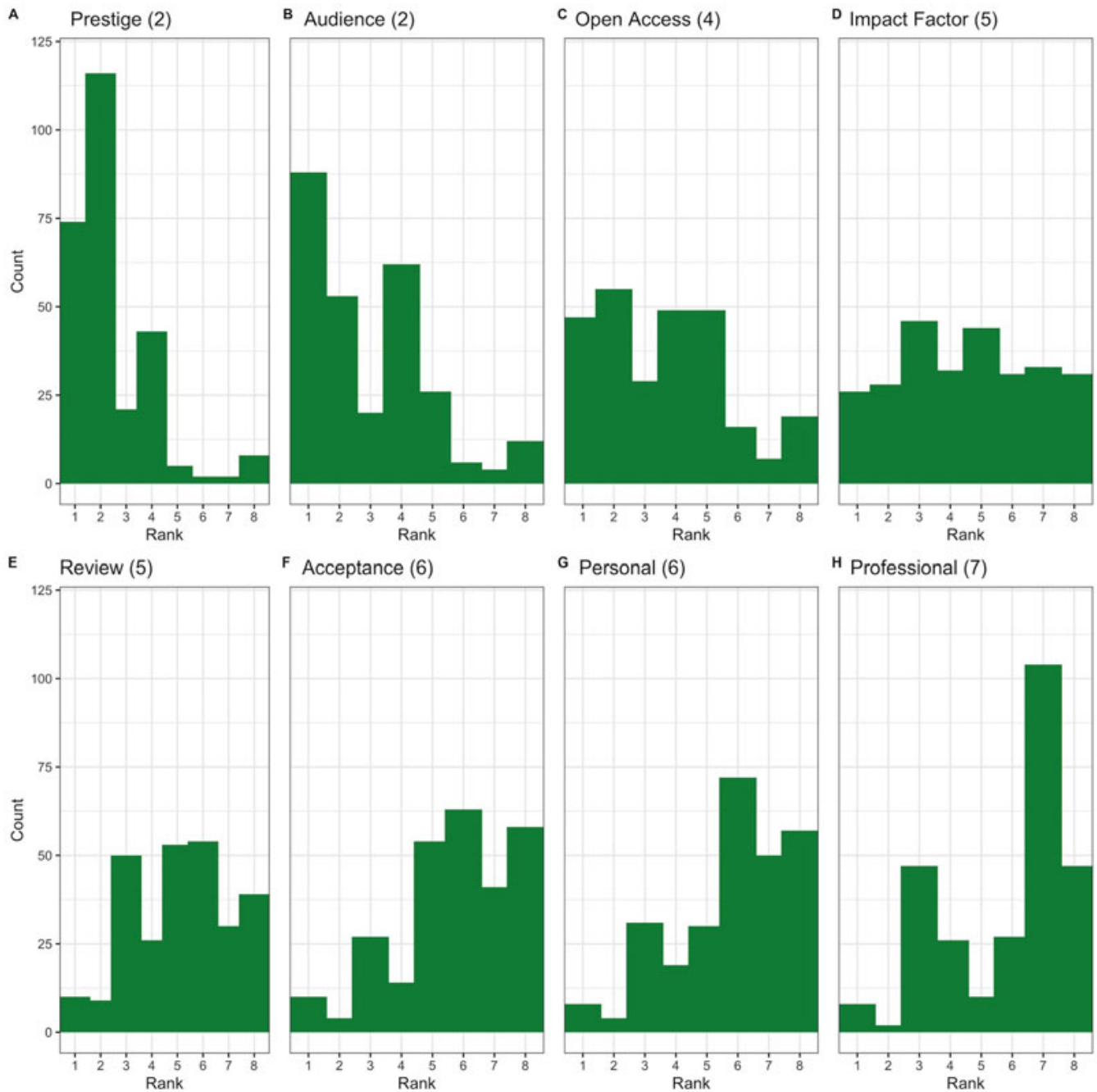

\section{G Personal (6)}

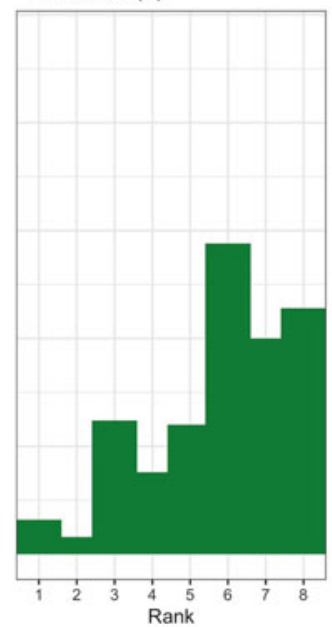

H Professional (7)

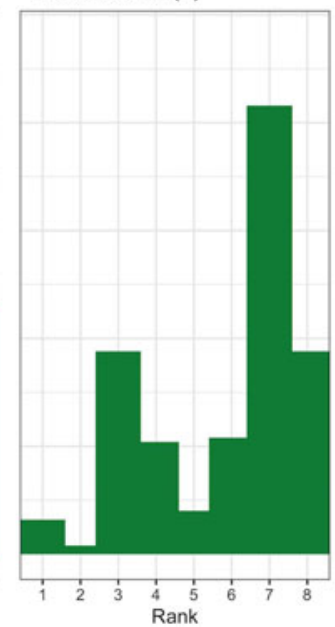

Figure 5. Histograms for each of the factors that respondents were asked to rank when deciding where to publish an academic article. Numeric values provided for each histogram represent the median rank for each factor.

respondents highlighted a variety of ethical stances in their open-ended responses that affect their publishing decisions. Ethical considerations were specifically linked to national or regional journals, and specifically to issues of access, by 10 respondents.

It's important to regularly submit articles to regional journals even though they are less prestigious because they are accessible to people in the part of the world where I work. (101)

I do not put US taxpayer-funded research on another nation's cultural heritage behind any pay wall that would prevent ... the people whose cultural heritage I study from reading it. (53)

These may in part be questions of audience (that is, who the typical or customary readership is likely to be) but they go beyond these to include access (that is, who has ready access to these publications). Language considerations are related to these issues and were mentioned by several respondents as relevant-for example, needing to publish whole articles or abstracts in languages other than English, or perceived but unwarranted biases that associated prestige with 
English-language publications. The normative hegemony of English in academic publication is well documented. At the same time, work conducted in some regions may require publication in regional journals in other languages.

If you work internationally, you may also face pressure/need to publish at least occasionally in regional, non-English-language journals in order to cultivate professional capital in your research area. This also goes for whether you work in an English-language setting or not: generally, I feel it's expected to publish in high-visibility, Englishlanguage journals, but you might face pressure to publish in your country's language to cultivate local goodwill. (19)

The economics of the academic publishing industry also attracted some attention and ire among our respondents. There is certainly an awareness among some respondents of the ethical critiques that have been leveled at commercial publishers, and Elsevier, Wiley, and Springer were identified as problematic platforms:

I am aware of and agree with the criticism of journals that are published by Elsevier or Springer, but as an early career academic, these are not considerations I can afford to act on. (131)

I am currently trying not to publish with Elsevier, because they are the devil. (164)

These responses are generally qualified, in the sense that they reflect an underlying desire to follow a principle, but they do not appear, based on our other data, to be motives that participants are willing or able to act on. This will be an important trend to be aware of as critiques of commercial academic publishers continue.

Two respondents expressed the importance of diversity in journal staff, authors, and editorial boards. As with the ethics of commercial publishers, although this view is not widely evident among our respondents, it is a factor worthy of future attention, given its recent relative prominence in discussions in several public forums.

Career Implications. Four respondents noted that career stage, independent of other factors, influenced their decisions about where to publish, emphasizing that venue choice has repercussions for career trajectories.

Journals which will allow [me] to make points in my career progression, unfortunately. (178)

To some degree, all archaeologists are motivated by factors related to career advancement, and these considerations are captured in part by specifically named factors in our survey, such as impact factor, acceptance rate, and prestige. Nonetheless, understanding academic publication from a life-course perspective highlights two points of disjuncture: hiring into a tenurestream position and the "tenure hurdle," which place particular burdens on early career researchers. The differences between the answers of non-tenure-stream and tenure-stream respondents to our questions should be understood in light of this perspective.

Relatedly, respondents sporadically noted specific issues in academic hierarchies that led them to particular publishing decisions. Academic collaborations are not free of inequality, so any individual's decisions may be influenced by the positions of their supervisors or higherranked collaborators within institutional or project hierarchies:

The pressure from my director to publish in a journal that is more "high prestige" than the research deserves. I mean, Nature does not care about 30 new AMS dates from blah blah during the Bronze Age. (206)

Logistical Considerations. Logistical considerations comprise technical issues surrounding the review and publication process beyond the duration of the review process. Eight respondents described financial considerations-specifically APCs - as affecting their decisions about where to submit manuscripts.

While some of the journals I rated are super important (to me at least), I find that charging $\$ 1,500$ to publish an accepted article is absurd. (231)

Many of the more prominent open access journals are "gold open access" (i.e., they carry APCs as a cost of publication), and this is a known issue limiting the popularity of open 
access publishing. Other logistical considerations advanced were the speed of publication after acceptance $(3 / 85,4 \%)$, word-count limits or figure limits $(7 / 85,8 \%)$, and the technological capacities and format of the journal $(7 / 85,8 \%)$. Language of publication, discussed above, can equally be considered an issue of logistics as well as one of equity, diversity, and access to findings. The respondents who expressed concern with journal format referenced the importance of color publishing, LaTeX submissions, the ability to associate supplemental datasets or metadata, the inclusion of nontraditional media, and the potential for digital archiving.

\section{Discussion}

The results of the PDIA survey confirm a number of our initial assumptions about the publishing landscape of academic archaeology.

First, our respondents indicated that prestige was the most important factor affecting their decisions about where to publish archaeological research. This result is in keeping with recent studies of anthropology and archaeology (Fulkerson and Tushingham 2019; Heath-Stout 2020a; Kawa et al. 2019) that demonstrate how various forms of academic prestige interdigitate with career opportunities and professional trajectories. It is necessary to recognize that "prestige," like "fit," is a culturally bound and semantically complex concept within academic discourse. Its nebulousness may be part of its value-a journal impact factor or quantitative ranking is less malleable and therefore less flexibly useful for strategic purposes. Accordingly, we acknowledge that our respondents' views of prestige may vary, and that our respondents may have somewhat different understandings of prestige than we do. Despite this malleability, its prominence renders the concept of prestige unavoidable in any discussion of publishing decisions.

Second, our results show that bibliometric indicators such as the SJR are inadequate proxies for journal prestige within the field of academic archaeology. The frequency with which particular titles were cited in our respondent-generated sample of journals showed only a weak relationship with SJR scores (Figure 3). "Journal impact factor" ranked lower than "Perceived prestige of journal" in the responses to Question 3 (Figure 5). One potential explanation for this result is that our respondents themselves treat bibliometric indicators as distinct from disciplinary understandings of prestige. This finding suggests that bibliometric indicators within archaeology should be treated with a grain of salt-an outcome that has meaningful implications for the use of such indicators for hiring, assessment, and promotion within the field.

Third, our survey demonstrates the diversity of available publication venues for archaeological research. There are more archaeology journals now than ever before. A search of Ulrich's serials directory reveals that 160 of 446 active, peer-reviewed archaeology journals $(36 \%)$ were started in this century; 47 of these $160(29 \%)$ are open access (Ulrich's Global Serials Directory 2020). However, the growth of journals across all disciplines is even more rapid-25,676/50,421 (51\%) of all active peerreviewed journals were started since 2001, of which 9,624 (38\%) are open access. Whether this rapid growth of journals is laudable is a matter for debate. Regardless, it is clear that despite growth in the field, archaeology journals are being developed more slowly and are lagging behind in open access, within the broader landscape of peer-reviewed journal publishing.

Finally, our survey identified areas of both internal consensus and disciplinary divergence concerning publishing decisions in academic archaeology, which are discussed in greater detail below.

\section{Areas of Consensus}

Our survey demonstrates intradisciplinary consensus on journal prestige at the high end of the spectrum. In other words, there are a few journals that the majority of academic archaeologists agree are particularly prestigious (Table 2). The top 12 journals from the responses to Questions 1 and 2 represent the top $10 \%$ of the sample of titles with available SJR scores $(n=122)$. Nine of the 12 titles appear on both lists, showing consensus regarding the journals that are crucial for both publishing archaeological research and adding value to CVs. The three journals that appear in the top five slots for both questions-Journal 
Table 2. Top 12 Journal Titles (Including SJR Scores, Start Years, and Subject Categories) from Question 1 and Question 2.

\begin{tabular}{|c|c|c|c|c|c|c|c|c|c|}
\hline \multicolumn{5}{|c|}{$\begin{array}{l}\text { QUESTION 1 } \\
\text { Journals that publish important archaeological research }\end{array}$} & \multicolumn{5}{|c|}{$\begin{array}{l}\text { QUESTION 2 } \\
\text { Journals that people who read archaeological academic CVs value the most }\end{array}$} \\
\hline Rank & Title & SJR & $\begin{array}{l}\text { Start } \\
\text { year }\end{array}$ & Subject category & Rank & Title & SJR & $\begin{array}{l}\text { Start } \\
\text { year }\end{array}$ & Subject category \\
\hline 1 & $\begin{array}{l}\text { Journal of Archaeological } \\
\text { Science }\end{array}$ & 1.72 & 1974 & Archaeology & 1 & $\begin{array}{l}\text { Journal of Archaeological } \\
\text { Science }\end{array}$ & 1.72 & 1974 & Archaeology \\
\hline 2 & Antiquity & 0.82 & 1927 & Archaeology & 2 & Science & 13.25 & 1880 & Sciences: Comprehensive Works \\
\hline 3 & American Antiquity & 1.24 & 1935 & Archaeology & 3 & Nature & 16.35 & 1869 & Sciences: Comprehensive Works \\
\hline 4 & $\begin{array}{l}\text { Journal of Anthropological } \\
\text { Archaeology }\end{array}$ & 1.30 & 1983 & $\begin{array}{l}\text { Anthropology, } \\
\text { Archaeology }\end{array}$ & 4 & Antiquity & 0.82 & 1927 & Archaeology \\
\hline 5 & Current Anthropology & 1.35 & 1955 & Anthropology & 5 & American Antiquity & 1.24 & 1935 & Archaeology \\
\hline 6 & PNAS & 5.60 & 1914 & $\begin{array}{l}\text { Sciences: Comprehensive } \\
\text { Works }\end{array}$ & 6 & PNAS & 5.60 & 1914 & Sciences: Comprehensive Works \\
\hline 7 & $\begin{array}{l}\text { Journal of Archaeological Method } \\
\text { and Theory }\end{array}$ & 1.29 & 1978 & Archaeology & 7 & Current Anthropology & 1.35 & 1955 & Anthropology \\
\hline 8 & Science & 13.25 & 1880 & $\begin{array}{l}\text { Sciences: Comprehensive } \\
\text { Works }\end{array}$ & 8 & American Anthropologist & 1.03 & 1888 & Anthropology \\
\hline 9 & Nature & 16.35 & 1869 & $\begin{array}{l}\text { Sciences: Comprehensive } \\
\text { Works }\end{array}$ & 9 & World Archaeology & 0.84 & 1969 & Archaeology \\
\hline 10 & World Archaeology & 0.84 & 1969 & Archaeology & 10 & $\begin{array}{l}\text { Journal of Anthropological } \\
\text { Archaeology }\end{array}$ & 1.30 & 1983 & Archaeology \\
\hline 11 & Journal of Archaeological Research & 1.71 & 1993 & Archaeology & 11 & $\begin{array}{l}\text { American Journal of } \\
\text { Archaeology }\end{array}$ & 0.49 & 1885 & Archaeology \\
\hline 12 & Cambridge Archaeological Journal & 0.86 & 1991 & Archaeology & 12 & PLOS One & 1.10 & 2006 & $\begin{array}{l}\text { Medical Sciences; Sciences: } \\
\text { Comprehensive Works }\end{array}$ \\
\hline
\end{tabular}

Note: Bolded journals occur in the top twelve for each question. 
of Archaeological Science, Antiquity, and American Antiquity - are all archaeology-subject publications. ${ }^{12}$ The primacy of these top-ranked archaeology journals demonstrates that although archaeologists are clearly conscious of the career ramifications of publishing in high-impact science-subject journals, these are not the only hallmarks of value within the discipline. Indeed, when the science-subject journals are removed, the top-ranking journals in our sample have relatively flat SJR scores. These results strongly suggest that the prestige of the top-ranked archaeology journals is not based on bibliometrics or citational weight but is instead related to disciplinary norms that consider these journals to be of the highest prestige. It is likely that the perceived prestige of particular journals is related to a number of intersecting and inextricable factors, including journals' "flagship" status in particular professional associations, name recognition, and journal age. Future research that investigates how each of these factors affects perceptions of prestige would be a valuable contribution to understanding knowledge production practices within the academy.

The demonstrated intradisciplinary agreement on the slate of top-tier journals has implications for the other major area of consensus revealed by our survey - the factors that affect publishing decisions. "Perceived prestige of journal" was the most important factor among our respondents, lending disciplinary norms concerning journal value increasing weight. Indeed, "perceived prestige of journal" was considered to be more critical than "journal impact factor," providing additional evidence that archaeologists clearly distinguish between disciplinary understandings of value and bibliometric measures of impact. This may in part be linked to audience-the second most important factor affecting publishing decisions, which explains the dominance of archaeology-subject journals in the top tier of Question 1 (66\%) and Question $2(50 \%)$ despite the negligible differences in these journals' SJR scores from the rest of the sample. Finally, it is encouraging that open access considerations ranked third in importance in respondents' replies to Question 3, showing that broader academic debates about the ethics and accessibility implications of publishing research in paywalled journals are resonating within archaeology.

\section{Areas of Divergence}

Despite the growing number of venues for the dissemination of archaeological work, the majority of the journals in our sample were cited by only a fraction of respondents (Table 3). For example, in response to Question 1, which asked about journals publishing important archaeological research, $90 \%$ of titles were cited by less than $10 \%$ of respondents, and $51 \%$ of the titles were cited by only a single respondent. In response to Question 2, which asked about journals that people who read archaeological academic CVs value most highly, $90 \%$ of titles were cited by less than $10 \%$ of respondents, and $44 \%$ of titles were cited by only a single respondent. The disparity in journals provided by respondents likely results from the proliferation of archaeology-subject journals over the last 50 years and the increasing fragmentation of the field (Hodder 2003), with different methodological and theoretical approaches producing their own subject-specific journals. ${ }^{13}$

The pattern revealed by our survey-agreement as to the prestige of the highest-ranked journals but lack of consensus below a certain threshold - is comparable to the prestige hierarchies generated by other fields. There has, for example, been a longitudinal program of research on perceptions of periodical prestige within library and information science (LIS). LIS practitioners have surveyed their field approximately once per decade since the 1980s, typically asking respondents to rank a core group of journals and select the five most important in the context of tenure and promotion (Blake 1996; Kohl and Davis 1985; Manzari 2013; Nisonger and Davis 2005).

The earliest LIS studies solicited data from a sample of American Research Library directors and American Library Association (ALA)accredited deans that revealed the existence of unique prestige hierarchies between the two groups but a "fundamental agreement on the rankings of two-thirds of the journals" (Kohl and Davis 1985:46). Only 10 years later, Blake's replication of the 1985 study revealed "scant evidence of substantial agreement on the relative 
Table 3. The Number of Times Respondents Listed a Particular Journal Title in Response to Questions 1 and 2.

\begin{tabular}{lcccc}
\hline \multicolumn{2}{c}{ Question 1 } & & \multicolumn{2}{c}{ Question 2 } \\
\cline { 1 - 2 } \cline { 5 - 5 } $\begin{array}{c}\text { Count } \\
\text { respondents }\end{array}$ & $\begin{array}{c}\text { Count titles } \\
(\%)\end{array}$ & & $\begin{array}{c}\text { Count } \\
\text { respondents }\end{array}$ & $\begin{array}{c}\text { Count titles } \\
(\%)\end{array}$ \\
\hline $1-10$ & $134(83)$ & & $1-10$ & $55(81)$ \\
$11-20$ & $9(6)$ & & $11-20$ & $5(7)$ \\
$21-30$ & $6(4)$ & & $21-30$ & $1(1)$ \\
$31-40$ & $3(2)$ & & $31-40$ & $0(0)$ \\
$41-50$ & $2(1)$ & & $41-50$ & $1(1)$ \\
$51-60$ & $3(2)$ & & $51-60$ & $0(0)$ \\
$61-70$ & $1(1)$ & & $61-70$ & $1(1)$ \\
$71-80$ & $1(1)$ & & $71-80$ & $1(1)$ \\
$>80$ & $3(2)$ & & $>80$ & $4(6)$ \\
\hline
\end{tabular}

Note: For example, in response to Question 1, 134 of the journal titles were listed by between 1 and 10 respondents, and 3 of the journal titles were listed by $>80$ respondents.

prestige" of sampled journals (Blake 1996:5), with statistically significant differences between the two groups for $47 \%$ of the sample, and internal consensus within groups occurring only for the top-tier journals. This consensus appears to be relatively stable within the LIS community: "the notable continuity over twenty years in the top five choices reinforce[s] the perception of an exceedingly high-prestige status for some elite journals" (Nisonger and Davis 2005:364). Overall, this research—showing a growing number of "core" journals, strong and stable internal consensus for a handful of topranking titles, disagreement as to the relative ranking of the bulk of the remaining journals, and prestige hierarchies that show "weak to practically nonexistent" correlations with citational data (Nisonger and Davis 2005:373)—presents clear parallels to our own results. Future research that seeks to determine whether such patterning in prestige hierarchies is characteristic of social sciences and humanities disciplines would be informative in understanding how different fields assess the relative value of publication venues.

As in the LIS studies, our survey revealed intergroup differences in journal assessments. When the mean SJR score for responses to Questions 1 and 2 was calculated for each respondent, two aspects of career stage and identity showed significant differences. First, there was a statistically significant difference between tenure-track and non-tenure-track respondents, with non-tenure-track respondents showing a significantly higher mean SJR score than tenuretrack respondents. Indeed, the mean SJR score broadly declines across career stages with higher SJR scores generally associated with early career respondents and lower SJR scores with more senior respondents (Figure 6). There are a number of factors that could be affecting this pattern, including the increasingly high pressures of the academic job market in archaeology and related fields, the growing expectations of qualifications for entry into $\mathrm{PhD}$ programs (Jones 2013), and shifting priorities over the course of researchers' careers. One respondent clearly outlined such considerations in response to Question 4:

I have delayed publishing work in regionally relevant journals to dedicate time and energy toward work designed for higher impact research in national/international journals as I have been given fairly clear indications that the tenure evaluation process (in particular at levels higher than my own academic unit) values contributions to highly ranked/ impact factor journals substantially more. My publication decision making process will likely shift to more heavily value the pertinence of the audience and to open access once I'm over the tenure hurdle. (141)

Such explanations are not, of course, mutually exclusive. Further research on the relationship between various forms of academic prestige and career considerations from an academic "life course" perspective could help to tease out the import of these factors in shaping publishing decisions.

Second, when the respondent sample was divided by gender, men showed a significantly higher mean SJR score than women for Question 2. This result is not unexpected given previous studies that have pointed to significant gendered differences in citational practices, authorship, and publishing behavior within the discipline. Research on the dynamics of knowledge production in North American archaeology has revealed a "lingering gap" in citations of women's work, which fall significantly below women's rates of publication (Hutson 2002). This citational gap is compounded by the "peer review gap" that has been demonstrated at multiple scales: 


\section{Career Stage}
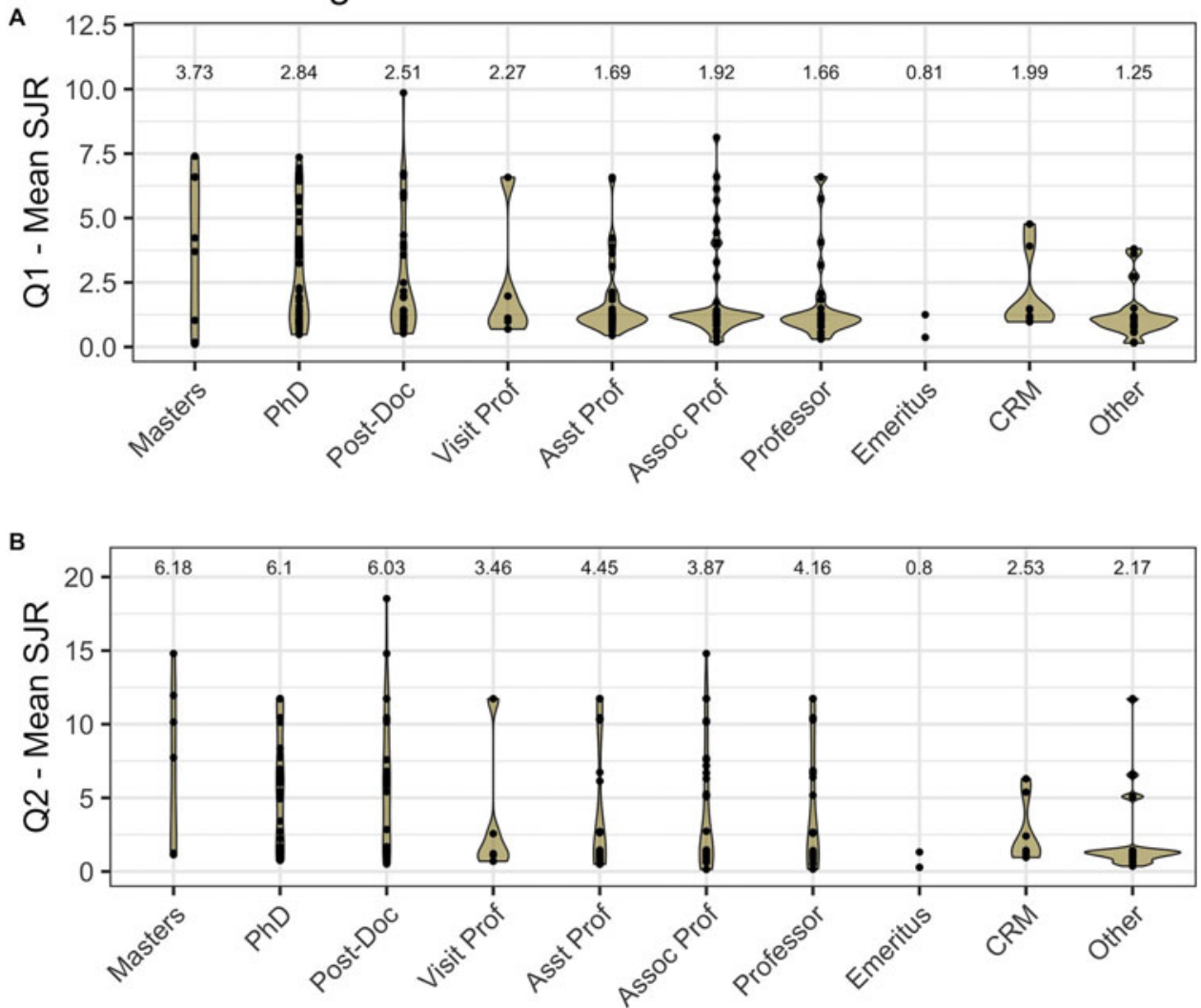

Figure 6. Violin plots of mean SJR scores subdivided by career stage.

women are underrepresented as authors in both regional and national peer-reviewed journals and are more likely to publish their work in nonrefereed venues (Bardolph 2014; Bardolph and Vanderwarker 2016; Fulkerson and Tushingham 2019; Gamble 2021; Rautman 2012; Tushingham et al. 2017). Although there are signs that the number of women authors is slowly moving toward parity, there are still "troublingly strong correlations between various prestige metrics and the overrepresentation of straight, white, cisgender men in journals" (Heath-Stout 2020a:15).

There is no evidence that these gendered patterns in authorship are consistently related to editorial bias (Rautman 2012), editor gender (Bardolph 2014), or prejudiced reviews that lead to higher rates of rejection for women (Bardolph 2014; Heath-Stout 2020b). Instead, the majority of studies show that men overwhelmingly submit a higher number of manuscripts to peer-reviewed journals, a disparity that has also been proffered to explain gendered disparities in the awards of major archaeological grants (Goldstein et al. 2018; Yellen 1994). Differential rates of both grant and journal submissions have been linked to the distinct personal and professional challenges faced by women in archaeology, including gendered disparities in mentorship, heavier teaching and service loads, and the time demands of childcare and domestic responsibilities that fall disproportionately on women. Given the ample research demonstrating significant differences in authorial behavior between men and women within academic archaeology, it is unsurprising that disciplinary understandings of prestige also differ by gender. Future research focusing on whether there are differences in how men and women talk and think about career-stage and life-course issues as factors motivating publication decisions 
could provide insight into the patterns revealed by our data. Additionally, studies investigating whether there are differences in how men and women talk about risk and uncertainty relating to submission to high-impact journals would complement existing research on gendered differences in authorial behavior and grant submissions within the discipline.

One final area of dissonance is shown by the disciplinary emphasis on publishing in sciencesubject journals. Whereas the top five journals that publish important archaeological research are all archaeology-subject or closely related journals, the top five journals considered key for adding value to $\mathrm{CVs}$ are a mixture of archaeology- and science-subject journals, suggesting that science journals are recognized as more prestigious when career considerations are at play. Tellingly, the science journals that have arguably the highest name recognition within all of academia-Science and Naturemove up in rank from Question 1 to Question 2. The prominence of a number of general science journals in the top tier of our survey results-particularly those renowned for their sizeable impact factors - suggests that academic archaeologists are well attuned to the prestige accorded to these journals in professional assessments within the academy (Niles et al. 2020; Schimanski and Alperin 2018).

The results of our survey therefore reveal the strong intradisciplinary consensus that highimpact science journals such as Science, Nature, and PNAS are coveted platforms for disseminating important archaeological research and also of high value to archaeological CVs. The primacy of these journals within the archaeological prestige hierarchy, however, is not reflected by the number of archaeology articles actually published in these venues. Using Web of Science (www.webofknowledge.com), a keyword search of the journal Science for articles categorized in the topic "archaeology" shows that only 103 articles have been published from 1964 to 2020; of these, 40 were published between 2010 and $2020 .^{14}$ Repeating this search for the journal Nature identifies 99 articles published in the period 1964-2020, of which 46 were published between 2010 and 2020. These search results suggest that over the last decade, these journals have published an average of four to five archaeology articles per year. The focus on certain kinds of archaeological research by high-impact science journals is well known (see Lyman et al. 2005:Figure 4), and if articles containing the keyword "DNA" are removed from this sample, the average drops to between three and four articles per year.

To some extent, the primacy of science journals can be explained by their considerable extradisciplinary prestige - a strategic consideration when focusing on publications that augment one's CV. It is worth underscoring, however, that Science and Nature also appear in the top $10 \%$ of journal titles listed for Question 1, suggesting that archaeologists do believe these are important venues for publishing their research, despite the relative rarity of that occurrence. The attraction to high-tier science journals may also be related to disciplinary aspirations relative to competing frameworks of knowledge production within the academy. The liminal positionality of archaeology - with ties to both the humanities and the sciences-has generated much debate about the divisions between the "two cultures" (sensu Snow 1962) within the discipline, a tension particularly evident in recent discussions of the rise of archaeogenetics as a method and research focus (Heyd 2017; Ion 2017; Kristiansen et al. 2017; Sørensen 2017; Vander Linden 2016). When viewed in this light, the perceived importance of venues such as Science and Nature can be interpreted as an assertion of the inherently scientific nature of archaeology and archaeological research. Given the cultural ascendance of science within the academy, with its attendant increases in funding and perceived social worth (Belfiore 2015), the ideological alignment of archaeology with hard science disciplines through its publishing aspirations-although not its publishing behavior-is perhaps unsurprising.

Our survey focused explicitly on perceptions of value within the discipline (where archaeologists would ideally submit their articles) rather than actual behavior (where archaeologists $d o$ submit their articles). Future research identifying the journals to which academic archaeologists typically submit their work for publication may help us to understand the paradox of the high 
disciplinary prestige of top-tier science journals despite the rare publication of archaeological research in such venues. Finally, because the composition of our sample of respondents was heavily skewed toward academic archaeologists in the United States and the United Kingdom, our results are geographically circumscribed. Future research examining publishing decisions made by academic archaeologists in other regions is necessary to better understand how such choices unfold in different parts of the world.

\section{Conclusions}

In their foundational study of perceptions of journal prestige, Kohl and Davis underscore that prestige hierarchies are "a phenomenon that has powerful consequences" (1985:41). The results of our survey have demonstrated that the perceptions of prestige that affect authorship (Fulkerson and Tushingham 2019; Heath-Stout 2020b), citational practices (Bardolph 2014), grant awards (Goldstein et al. 2018), job prospects, and professional trajectories (Kawa et al. 2019) in academic archaeology are also intricately entangled with decisions about where to publish the results of archaeological research.

Prestige was the most important factor affecting respondents' decisions about where to publish-more important to archaeological authors than audience, open access, or journal impact factors. Given that the prestige of archaeological publication venues does not show a strong relationship to bibliometric indicators, it is tempting to argue that the concept is so nebulous and imprecise as to be of little utility for discussions of knowledge production within the discipline. The existence of a strong internal consensus regarding the top-tier journals for publishing important archaeological research and bolstering academic CVs, however, demonstrates that archaeologists share consistent understandings of the most valuable journals in the field.

The coherent conceptualization of journal prestige within archaeology suggests that the field has much in common with social science disciplines such as library and information science. The results of our survey, however, point to aspirations for a different set of disciplinary alignments. Archaeologists' publishing hierarchies share a fixation with high-impact science-subject journals such as Science and Nature, a fixation that is outsized relative to the amount of archaeological research actually published by these venues. The magnetism of science journals is likely linked to their highly lauded status within the academy, the ascendancy of the archaeological sciences within the discipline, and the public appetite for archaeogenetics research. It is, however, important to acknowledge the paradoxical nature of the disciplinary preoccupation with these journals given that the likelihood of the average archaeologist publishing in one of these venues is vanishingly small.

Although the popular aphorism is "publish or perish," our work indicates that "prestige or perish" might be a more appropriate maxim, both in regard to publishing decisions and to the knowledge production apparatus in academic archaeology more generally. This finding is troubling in light of recent research demonstrating that academic prestige is inherently inequitable. It is distributed differentially between institutions, departments, and individuals largely as the result of institutional networks and unequal access to social and financial capital rather than being based on productivity or merit (Kawa et al. 2019). The enduring academic emphasis on prestige, in tandem with its uneven distribution across the academy, has implications for the representativeness of disciplinary research, and by association, the representativeness of our understanding of the past. As Heath-Stout's work has recently highlighted, "the most prestigious venues for the dissemination of archaeological knowledge remain the least diverse" (2020a: 16), suggesting that the inequities woven into our current systems of academic prestige continue to replicate themselves.

There is work to be done on multiple levels to confront these issues. Research has identified myriad systemic problems in the structure of the academic publishing industry - from the skyrocketing costs of institutional journal subscriptions to the uncompensated labor of peer review and the ethics of paywalling the results of publicly funded research. The high ranking of open access considerations by our survey respondents suggests that archaeologists are well aware of these inequities and are invested 
in challenging the coercive norms of the academic publishing industry. Another dimension to publishing decisions, however, is ideological. A system of relatively untested and unquestioned precepts-that journal prestige is correlated with merit, that our prestige hierarchies are held in common, that high-impact science-subject journals are ideal venues for archaeological research - underlies our disciplinary understandings of value. These assumptions affect not just what and where we publish but how we evaluate fellow scholars when we read their CVs and evaluate their suitability for academic positions. Like many other symbolic systems, prestige is real because we make it so. Our strong disciplinary agreement as to its primacy, however, suggests that understandings of prestige will continue to have concrete and long-lasting impacts on the field of archaeology.

Acknowledgments. Laura Heath-Stout (University of Massachusetts Boston), Ben Marwick (University of Washington), and Andre Costopoulos (Universty of Alberta) shared resources and discussed aspects of archaeology and academic publishing. Nick Kawa (Ohio State University) shared resources and discussed anthropology and prestige. Jonathan Powell (University of Central Florida) and Cameron Brick (University of Amsterdam) provided context for prestige hierarchies in psychology and political science, respectively. This research has received funding from the European Union's Horizon 2020 research and innovation programme under the Marie Skłodowska-Curie grant agreement No. 746216 and the Renfrew Fellowship, which is sponsored by the McDonald Institute for Archaeological Research at the University of Cambridge. We thank the two reviewers whose constructive comments improved this manuscript.

Data Availability Statement. All data used in this analysisincluding the cleaned data, Ulrich's metadata, workflow and code for the data transformation, and analysis for the PDIA survey - can be found in the online repository for this project at https://doi.org/10.6084/m9.figshare.c.5256425 or https:// github.com/erikgjes/Prestige-or-Perish-Publishing-Decisionsin-Academic-Archaeology.

Supplemental Material. For supplemental material accompanying this article, visit https://doi.org/10.1017/aaq.2021.64.

1. Supplemental Data 1. List of 167 journal titles generated by respondents, including SJR score, $h$-index, and Ulrich's metadata.

2. Supplemental Data 2. Survey results: Demographic and professional information and Questions 1-3.

3. Supplemental Data 3. Composition of respondent-generated journal titles by serial type, format, country of publication, start decade, text language, and subject.

4. Supplemental Data 4. Survey results: demographic and professional information and Question 4.

\section{Notes}

1. Although, perhaps unsurprisingly, spending less time per reading on average.

2. For social sciences and humanities fields, these are Wiley-Blackwell, Reed-Elsevier, Springer, Taylor \& Francis, and Sage Publications.

3. The SCImago Journal \& Country Rank website (https://www.scimagojr.com/journalrank.php) includes two subject categories specific to archaeology: "Archeology" and "Archeology (Arts and Humanities)."

4. A recent study of authorship in 21 peer-reviewed archaeology journals noted that the impact factor of the journal Science was 41.063 in 2016, whereas the impact factor of the sampled archaeology journals ranged from 0.52 to 3.31 for the same period (Heath-Stout 2020a:9).

5. See Costopoulos (2017b) for a discussion of how the "traditional prestige economy" of archaeology presents obstacles to implementing open access policies within the discipline.

6. For the curious, these were American Antiquity, Latin American Antiquity, Journal of Archaeological Method and Theory, Journal of Archaeological Research, and Journal of Field Archaeology.

7. The most notable changes to the survey were (1) defining specific career stage options for respondents to select, given that there was a high level of response variability to this question in the first survey that required significant data cleaning; (2) removing the third question ("What do you think are the five journals that publish important archaeological research that have the highest journal impact factor (JIF)?" from the second half of the survey because it produced redundant results relative to the first two questions; and (3) asking participants to rank their provided journal names so as to give us more statistical power and better investigate perceptions of prestige.

8. https://www.qualtrics.com/support/survey-platform/ getting-started/qualtrics-gdpr-compliance/.

9. For example, to calculate the 2021 impact factor of a journal, one would count the total number of times articles published in 2019 and 2020 were cited in 2021, dividing that number by the total number of articles published in that journal in 2019 and 2020.

10. Although their survey focuses on archaeologists working in the southeastern United States, Bardolph and Vanderwarker (2016) offer a detailed and informative exploration of the relationships between publishing behavior and different types of archaeological careers, including CRM.

11. Numbers are de-identified indicators of unique respondents.

12. In the following discussion, we use the term "archaeology-subject" to refer to journals that Ulrich's directory classifies as falling within the subject area "archaeology," and we use "science-subject" to refer to journals that Ulrich's directory classifies as falling within the subject area "Sciences: Comprehensive Works."

13. Heath-Stout (2020b) outlines data that demonstrate significant demographic differences in methodological specialization within the discipline-with digital and field methods dominated by men, and art history and laboratory methods dominated by women-a division that may also produce specialization-specific understandings of journal prestige that are affected by gender.

14. There is no "discipline" category for archaeology, so we used "topic," which searches title/abstract/keywords. Instead of just "archaeology," we used the terms 
"archaeolog*" and "archeolog*" to catch articles that use alternate spellings and derived terms. The earliest year for which data were available was 1964 .

\section{References Cited}

Antell, Karen, Joe S. Foote, and Jody Bales Foote

2016 Scholarly Publishing's Evolving Landscape: Impact Metrics, Electronic-Only Journals, and Open Access in Journalism and Communication Research. Journalism and Mass Communication Educator 71:309-328. DOI:10.1177/1077695816668864.

Barber, Sarah (editor)

2012 Special Forum. Life in Ruins: Work-Life Balance in Archaeology. SAA Archaeological Record 12(5):26-36.

Bardolph, Dana N.

2014 A Critical Evaluation of Recent Gendered Publishing Trends in American Archaeology. American Antiquity 79:522-540. DOI:10.7183/0002-7316.79.3.522.

2018 Controlling the Narrative: A Comparative Examination of Gendered Publishing Trends in the SCA and Beyond. California Archaeology 10:159-186. DOI:10. 1080/1947461X.2018.1535813.

Bardolph, Dana N., and Amber M. Vanderwarker

2016 Sociopolitics in Southeastern Archaeology: The Role of Gender in Scholarly Authorship. Southeastern Archaeology 35:175-193. DOI:10.1080/0734578X. 2015.1113101.

Bartholomew, Robert E.

2014 Science for Sale: The Rise of Predatory Journals. Journal of the Royal Society of Medicine 107:384385. DOI:10.1177/0141076814548526.

Baxter, Jane Eva

2005 Gendered Perceptions of Archaeology: A Perspective from the SAA Member Needs Assessment Survey. SAA Archaeological Record 5(4):7-9.

Beall, Jeffrey

2020 Beall's List of Potential Predatory Journals and Publishers. Electronic document, https://beallslist.net/ standalone-journals/, accessed August 7, 2020.

Belfiore, Eleonora

2015 "Impact," "Value" and "Bad Economics": Making Sense of the Problem of Value in the Arts and Humanities. Arts and Humanities in Higher Education 14:95110. DOI:10.1177/1474022214531503.

Blake, Virgil L. P.

1996 The Perceived Prestige of Professional Journals, 1995: A Replication of the Kohl-Davis Study. Education for Information 14(3):157-179. DOI:10.3233/EFI-1996-14301.

Bornmann, Lutz, Andreas Thor, Werner Marx, and Hermann Schier

2016 The Application of Bibliometrics to Research Evaluation in the Humanities and Social Sciences: An Exploratory Study Using Normalized Google Scholar Data for the Publications of a Research Institute. Journal of the Association for Information Science and Technology 67:2778-2789. DOI:10.1002/asi.

Clancy, Kathryn B. H., Robin G. Nelson, Julienne N. Rutherford, and Katie Hinde

2014 Survey of Academic Field Experiences (SAFE): Trainees Report Harassment and Assault. PLoS ONE 9(7):e102172. DOI:10.1371/journal.pone.0102172.

Colaninno, Carol E., Shawn P. Lambert, Emily L. Beahm, and Carl G. Drexler

2020 Creating and Supporting a Harassment- and Assault-
Free Field School. Advances in Archaeological Practice 8:111-122. DOI:10.1017/aap.2020.8.

Costopoulos, Andre

2017a The Post-Journal Academic Publishing Landscape. ArcheoThoughts (blog), September 13, 2017. https:// archeothoughts.wordpress.com/2017/09/13/the-postjournal-academic-publishing-landscape/, accessed July 23, 2020.

2017b The Traditional Prestige Economy of Archaeology Is Preventing Its Emergence as an Open Science. ArcheoThoughts (blog), May 17, 2017. https:/ archeothoughts.wordpress.com/2017/05/17/the-traditionalprestige-economy-of-archaeology-is-preventing-itsemergence-as-an-open-science/, accessed October 1, 2020.

2018 Limiting the Damage of Disengaging from the Academic Journal System. ArcheoThoughts (blog), May 3 , 2018. https://archeothoughts.wordpress.com/2018/05/ 03/limiting-the-damage-of-disengaging-from-the-journalsystem/, accessed July 23, 2020.

D'Andrade, Roy G., and Claudia Strauss (editors)

1992 Human Motives and Cultural Models. Cambridge University Press, Cambridge.

Demir, Selcuk Besir

2018 Predatory Journals: Who Publishes in Them and Why? Journal of Informetrics 12:1296-1311. DOI:10. 1016/j.joi.2018.10.008.

Else, Holly

2020 Nature Journals Reveal Terms of Landmark OpenAccess Option. Electronic document, https://www. nature.com/articles/d41586-020-03324-y, accessed January $19,2021$.

Falagas, Matthew E., Vasilios D. Kouranos, Ricardo Arencibia-Jorge, and Drosos E. Karageorgopoulos

2008 Comparison of SCImago Journal Rank Indicator with Journal Impact Factor. FASEB Journal 22:26232628. DOI:10.1096/fj.08-107938.

Fogelin, Lars

2019 An Unauthorized Companion to American Archaeological Theory. Electronic document, https://arizona. academia.edu/LarsFogelin, accessed July 15, 2020.

2020 What I Learned Writing an Archaeological Theory Book and Giving It Away for Free. SAA Archaeological Record 20(1):35-37.

Fulkerson, Tiffany J., and Shannon Tushingham

2019 Who Dominates the Discourses of the Past? Gender, Occupational Affiliation, and Multivocality in North American Archaeology Publishing. American Antiquity 84:379-399. DOI:10.1017/aaq.2019.35.

Gamble, Lynn H.

2021 Editor's Corner. American Antiquity 86:221-223. DOI:10.1017/aaq.2021.26.

Gantz, Paula

2013 Journal Print Subscription Price Increases No Longer Reflect Actual Costs. Learned Publishing 26:206-210. DOI:10.1087/20130309.

Gaspar, Deborah B. and Ann K. G. Brown

2015 Hiring in an Academic Library: Fit Is Essential. College and Undergraduate Libraries 22:374-386.

Gero, Joan M.

1985 Socio-Politics and the Woman-at-Home Ideology. American Antiquity 50:342-350.

Gero, Joan M., David M. Lacy, and Michael L. Blakey (editors)

1983 The Socio-Politics of Archaeology. Research Reports No. 23. University of Massachusetts, Amherst. 
Goldstein, Lynne, Barbara J. Mills, Sarah Herr, Jo Ellen Burkholder, Leslie Aiello, and Christopher Thornton

2018 Why Do Fewer Women Than Men Apply for Grants after Their PhDs? American Antiquity 83:367-386. DOI:10.1017/aaq.2017.73.

Hawkes, Jacquetta

1968 The Proper Study of Mankind. Antiquity 42:255262.

Heath-Stout, Laura E.

2019 Diversity, Identity, and Oppression in the Production of Archaeological Knowledge. PhD dissertation, Department of Anthropology, Boston University, Boston.

2020a Who Writes about Archaeology? An Intersectional Study of Authorship in Archaeological Journals. American Antiquity. 85:407-426. DOI:10.1017/aaq.2020.28.

2020b Guest Editorial Introduction: Gender, Equity, and the Peer Review Process at the Journal of Field Archaeology. Journal of Field Archaeology 45:135-139. DOI:10.1080/00934690.2020.1719295.

Heath-Stout, Laura E., and Elizabeth M. Hannigan

2020 Affording Archaeology: How Field School Costs Promote Exclusivity. Advances in Archaeological Practice 8:123-133. DOI:10.1017/aap.2020.7.

Heyd, Volker

2017 Kossinna's Smile. Antiquity 91:348-359. DOI:10. 15184/aqy.2017.21

Hirsch, Jorge E

2005 An Index to Quantify an Individual's Scientific Research Output. PNAS 102:16569-16572. DOI:10. 1073/pnas.0507655102.

Hodder, Ian

2003 Archaeology as a Discontinuous Domain. In Essential Tensions in Archaeological Method and Theory, edited by Todd L. VanPool and Christine S. VanPool, pp. 5-9. University of Utah Press, Salt Lake City.

Huggett, Jeremy

2015 Digital Haystacks: Open Data and the Transformation of Archaeological Knowledge. In Open Source Archaeology: Ethics and Practice, edited by Andrew T. Wilson and Ben Edwards, pp. 6-29. DeGruyter Open, Warsaw/Berlin.

Hutson, Scott R.

2002 Gendered Citation Practices in American Antiquity and Other Archaeology Journals. American Antiquity 67:331-342. DOI: $10.2307 / 2694570$.

Ion, Alexandra

2017 How Interdisciplinary Is Interdisciplinarity? Revisiting the Impact of aDNA Research for the Archaeology of Human Remains. Current Swedish Archaeology 25:177-198.

Isaac, Glynn LL.

1971 Whither Archaeology? Antiquity 45:39-60. DOI:10. 1017/S0003598X00069039.

Jalbert, Catherine L.

2019 Archaeology in Canada: An Analysis of Demographics and Working Conditions in the Discipline. PhD dissertation, Department of Archaeology Memorial University of Newfoundland, St. John's.

Jobson, Ryan Cecil

2020 The Case for Letting Anthropology Burn: Sociocultural Anthropology in 2019. American Anthropologist 122:259-271. DOI:10.1111/aman. 13398.

Jones, Michael

2013 Issues in Doctoral Studies-Forty Years of Journal Discussion: Where Have We Been and Where Are We
Going? International Journal of Doctoral Studies 8:83-104. DOI:10.28945/1871.

Kawa, Nicholas C., José A. Clavijo Michelangeli, Jessica L. Clark, Daniel Ginsberg, and Christopher McCarty

2019 The Social Network of US Academic Anthropology and Its Inequalities. American Anthropologist 121:14 29. DOI:10.1111/aman.13158.

Khoo, Shaun Yon Seng

2019 Article Processing Charge Hyperinflation and Price Insensitivity: An Open Access Sequel to the Serials Crisis. LIBER Quarterly 29(1):1-18. DOI:10.18352/lq.10280.

Kohl, David F., and Charles Hargis Davis

1985 Ratings of Journals by ARL Library Directors and Deans of Library and Information Science Schools. College \& Research Libraries 46(1):40-47. DOI:10.5860/ crl_46_01_40.

Kosmopoulos, Christine, and Denise Pumain

2007 Citation, Citation, Citation: Bibliometrics, the Web and the Social Sciences and Humanities. Cybergeo: European Journal of Geography, Science et Toile:Article 411. DOI:10.4000/cybergeo. 15463.

Kristiansen, Kristian, Morten E. Allentoft, Karin M. Frei, Rune Iversen, Niels N. Johannsen, Guus Kroonen, Łukasz Pospieszny, et al.

2017 Re-Theorising Mobility and the Formation of Culture and Language among the Corded Ware Culture in Europe Antiquity 91:334-347. DOI:10.15184/aqy.2017.17.

Lake, Mark

2012 Open Archaeology. World Archaeology 44:471478. DOI:10.1080/00438243.2012.748521.

Larivière, Vincent, Stefanie Haustein, and Philippe Mongeon

2015 The Oligopoly of Academic Publishers in the Digital Era. PLoS ONE 10(6):e0127502. DOI:10.1371/journal. pone. 0127502 .

Leighton, Mary

2020 Myths of Meritocracy, Friendship, and Fun Work: Class and Gender in North American Academic Communities. American Anthropologist 122:444-458. DOI:10.1111/aman.13455.

Lyman, R. Lee, Michael J. O'Brien, and Michael Brian Schiffer

2005 Publishing Archaeology in Science and Scientific American, 1940-2003. American Antiquity 70:157-167. DOI: $10.2307 / 40035274$.

Manzari, Laura

2013 Library and Information Science Journal Prestige as Assessed by Library and Information Science Faculty. Library Quarterly: Information, Community, Policy 83(1):42-60.

Martinón-Torres, Martin, and David Killick

2015 Archaeological Theories and Archaeological Sciences. In Oxford Handbook of Archaeological Theory, edited by Andrew Gardner, Mark Lake, and Ulrike Sommer. Oxford University Press, Oxford. DOI:10. 1093/oxfordhb/9780199567942.013.004.

Marwick, Ben, Jade d'Alpoim Guedes, C. Michael Barton, Lynsey A. Bates, Michael Baxter, Andrew Bevan, Elizabeth A. Bollwerk, et al.

2017 Open Science in Archaeology. SAA Archaeological Record 17(4):8-14.

Marwick, Ben, and Suzanne E. Pilaar Birch

2018 A Standard for the Scholarly Citation of Archaeological Data as an Incentive to Data Sharing. Advances in Archaeological Practice 6:125-143. DOI:10.1017/ aap.2018.3.

McGuigan, Glenn S.

2004 Publishing Perils in Academe: The Serials Crisis and 
the Economics of the Academic Journal Publishing Industry. Journal of Business and Finance Librarianship 10(1):13-26. DOI:10.1300/J109v10n01_03.

Meskell, Lynn

2002 The Intersections of Identity and Politics in Archaeology. Annual Review of Anthropology 31:279-301. DOI:10.1146/annurev.anthro.31.040402.085457.

Meyers, Maureen S., Elizabeth T. Horton, Edmond A. Boudreaux, Stephen B. Carmody, Alice P. Wright, and Victoria G. Dekle

2018 The Context and Consequences of Sexual Harassment in Southeastern Archaeology. Advances in Archaeological Practice 6:275-287. DOI:10.1017/aap.2018.23.

Moser, Stephanie

2007 On Disciplinary Culture: Archaeology as Fieldwork and Its Gendered Associations. Journal of Archaeological Method and Theory 14:235-263. DOI:10. 1007/s10816-007-9033-5.

Nederhof, Anton J.

2006 Bibliometric Monitoring of Research Performance in the Social Sciences and the Humanities: A Review. Scientometrics 66:81-100.

Nelson, Margaret C., and Deborah L. Crooks

1994 Dual Anthropology Career Couples: Different Strategies and Different Success Rates. Archeological Papers of the American Anthropological Association 5:59-64. DOI:10.1525/ap3a.1994.5.1.59.

Nelson, Robin G., Julienne N. Rutherford, Katie Hinde, and Kathryn B. H. Clancy

2017 Signaling Safety: Characterizing Fieldwork Experiences and Their Implications for Career Trajectories. American Anthropologist 119:710-722. DOI:10.1111/ aman.12929.

Niles, Meredith T., Lesley A. Schimanski, Erin C. McKiernan, and Juan Pablo Alperin

2020 Why We Publish Where We Do: Faculty Publishing Values and Their Relationship to Review, Promotion and Tenure Expectations. PLOS ONE 15(3):e0228914. DOI:10.1371/journal.pone.0228914.

Nisonger, Thomas E., and Charles H. Davis

2005 The Perception of Library and Information Science Journals by LIS Education Deans and ARL Library Directors: A Replication of the Kohl-Davis Study. College and Research Libraries 66(4):341-377. DOI:10. 5860/crl.66.4.341.

Norris, Michael, and Charles Oppenheim

2010 The H-Index: A Broad Review of a New Bibliometric Indicator. Journal of Documentation 66(5):681-705. DOI:10.1108/00220411011066790.

Overholtzer, Lisa, and Catherine L. Jalbert

2021 A "Leaky" Pipeline and Chilly Climate in Archaeology in Canada. American Antiquity 86:261-282. DOI:10.1017/aaq.2020.107.

Radde, Hugh D.

2018 Sexual Harassment among California Archaeologists: Results of the Gender Equity and Sexual Harassment Survey. California Archaeology 10:231-255. DOI:10.1080/1947461X.2018.1535816.

Rautman, Alison E.

2012 Who Gets Published in American Antiquity? SAA Archaeological Record 12(2):25-30.

$\mathrm{R}$ Core Team

2020 R: A Language and Environment for Statistical Computing. R Foundation for Statistical Computing, Vienna, Austria. Electronic document, https://www.Rproject.org/, accessed October 10, 2020.
Schimanski, Lesley A., and Juan Pablo Alperin

2018 The Evaluation of Scholarship in Academic Promotion and Tenure Processes: Past, Present, and Future. F1000Research 7:1605. DOI:10.12688/f1000research. 16493.1.

Seglen, P. O.

1997 Citations and Journal Impact Factors: Questionable Indicators of Research Quality. Allergy: European Journal of Allergy and Clinical Immunology 52:1050-1056. DOI:10.1111/j.1398-9995.1997.tb00175.x.

Shore, Cris, and Susan Wright

2000 Coercive Accountability: The Rise of Audit Culture in Higher Education. In Audit Cultures: Anthropological Studies in Accountability, Ethics and the Academy, edited by Marilyn Strathern, pp. 57-89. Routledge, London.

Snow, C. P.

1962 The Two Cultures. Spectator, London.

Sørensen, Tim Flohr

2017 The Two Cultures and a World Apart: Archaeology and Science at a New Crossroads. Norwegian Archaeological Review 50:101-115. DOI:10.1080/00293652. 2017.1367031.

Speakman, Robert J., Carla S. Hadden, Matthew H. Colvin, Justin Cramb, K. C. Jones, Travis W. Jones, Corbin L. Kling, et al.

2018 Choosing a Path to the Ancient World in a Modern Market: The Reality of Faculty Jobs in Archaeology. American Antiquity 83:1-12. DOI:10.1017/aaq.2017.36.

Speakman, Robert J., Carla S. Hadden, Matthew H. Colvin, Justin Cramb, K. C. Jones, Travis W. Jones, Isabelle Lulewicz, et al.

2018 Market Share and Recent Hiring Trends in Anthropology Faculty Positions. PLOS ONE 13(9):e0202528. DOI:10.1371/journal.pone.0202528.

Strathern, Marilyn (editor)

2000 Audit Cultures: Anthropological Studies in Accountability, Ethics, and the Academy. Routledge, London.

Tenopir, Carol, Donald W. King, Sheri Edwards, and Lei Wu

2009 Electronic Journals and Changes in Scholarly Article Seeking and Reading Patterns. Aslib Proceedings 61(1):5-32. DOI:10.1108/00012530910932267.

Tushingham, Shannon, Tiffany Fulkerson, and Katheryn Hill

2017 The Peer Review Gap: A Longitudinal Case Study of Gendered Publishing and Occupational Patterns in a Female-Rich Discipline, Western North America (1974-2016). PLOS ONE 12(11):e0188403. DOI:10. 1371/journal.pone.0188403.

Ulrich's Global Serials Directory

2020 Ulrich's Global Serials Directory. Electronic document, http://ulrichsweb.serialssolutions.com/login, accessed December 11, 2020.

Vander Linden, Marc

2016 Population History in Third-Millennium-BC Europe: Assessing the Contribution of Genetics. World Archaeology 48:714-728. DOI:10.1080/00438243. 2016.1209124.

Van Noorden, Richard

2013 Open Access: The True Cost of Science Publishing. Nature 495:426-429. DOI:10.1038/495426a.

Voss, Barbara L

2021a Documenting Cultures of Harassment in Archaeology: A Review and Analysis of Quantitative and Qualitative Research Studies. American Antiquity 86:244-260. DOI:10.1017/aaq.2020.118. 
2021b Disrupting Cultures of Harassment in Archaeology: Social-Environmental and Trauma-Informed Approaches to Disciplinary Transformation. American Antiquity 86:447-464. DOI:10.1017/aaq.2021.19.

Wenzler, John

2017 Scholarly Communication and the Dilemma of Collective Action: Why Academic Journals Cost Too Much. College and Research Libraries 78(2):183200. DOI:10.5860/crl.78.2.183.

White, William, and Catherine Draycott

2020 Why the Whiteness of Archaeology Is a Problem. Sapiens, July 7, 2020. Electronic document, https:// www.sapiens.org/archaeology/archaeology-diversity/, accessed December 30, 2020.

Wickham, Hadley, Mara Averick, Jennifer Bryan, Winston Chang, Lucy D'Agostino McGowan, Romain François, Garrett Grolemund, et al.

2019 Welcome to the Tidyverse. Journal of Open Source Software 4(43):1686. DOI:10.21105/joss.01686.

Wilson, Andrew T., and Ben Edwards (editors)

2015 Open Source Archaeology: Ethics and Practice. DeGruyter Open, Warsaw/Berlin.
Wylie, Alison

1993 Workplace Issues for Women in Archaeology: The Chilly Climate. In Women in Archaeology: A Feminist Critique, edited by Hilary du Cros and Laurajane Smith, pp. 245-258. Occasional Papers in Prehistory 23. Australian National University, Department of Prehistory, Research School of Pacific Studies, Canberra.

Xia, Jingfeng, Jennifer L. Harmon, Kevin G. Connolly, Ryan M. Donnelly, Mary R. Anderson, and Heather A. Howard 2015 Who Publishes in "Predatory" Journals? Journal of the Association for Information Science and Technology 66:1406-1417. DOI:10.1002/asi.23265.

Yellen, John E.

1994 Women, Archeology, and the National Science Foundation: An Analysis of Fiscal Year 1989 Data. Archaeological Papers of the American Anthropological Association 5(1):53-57. DOI:10.1525/ap3a.1994.5.1.53.

Submitted January 19, 2021; Revised May 20, 2021;

Accepted June 11, 2021 